\title{
Obstáculos en la activación de derechos en el marco de la defensa penitenciaria chilena ${ }^{1}$
}

\author{
Obstacles to the mobilization of rights \\ in cases of prisoner defense in Chile
}

\author{
Jörg Alfred Stippel ${ }^{2}$ \\ Universidad Autónoma de Chile - Santiago/Chile \\ jorg.stippel@uautonoma.cl \\ http://orcid.org/0000-0002-8465-7020
}

Paula Carolina Medina ${ }^{3}$

Universidad Central de Chile - Santiago/Chile

pmedinag@ucentral.cl

http://orcid.org/0000-0001-8356-3025

\begin{abstract}
Rodrigo Lillo ${ }^{4}$
Universidad Central de Chile - Santiago/Chile

rodrigolillovera@gmail.com

http://orcid.org/0000-0001-8763-7386
\end{abstract}

1 El desarrollo de la parte empírica de este trabajo fue financiado por el Fondo Interno de Investigación I+D 2016, Código CIP16018. Universidad Central de Chile.

2 Doctor en Derecho de la Universidad de Bremen, Alemania. Investigador de la Universidad Autónoma de Chile.

3 Psicóloga, Universidad de Chile; Magíster en Criminología, Universidad Central de Chile; y Magíster en Métodos de Investigación Social, Universidad Diego Portales (en proceso de titulación). Es también Diplomada en Metodologías Cualitativas de Investigación Social, Universidad Diego Portales y tiene un Postítulo en Justicia, derechos y políticas públicas para la infancia y adolescencia, por la misma universidad. Actualmente se desempeña como docente, investigadora y directora del Magíster en Criminología y Justicia Penal, de la Facultad de Derecho y Humanidades de la Universidad Central.

4 Magíster en Criminología y Justicia Penal (Universidad Central de Chile); Abogado Defensoría Penal Pública; Santiago de Chile. 
Resumen: Al cumplirse una década del inicio de la Defensa Penitenciaria chilena, el artículo indaga sobre factores institucionales que pueden incidir en la activación de los derechos de los condenados privados de libertad. Nos preguntamos ¿si la atención que brinda la Defensa Penitenciaria es un fiel reflejo de la demanda de defensa expresada por las personas condenadas, o si responde a decisiones de política institucional de la Defensa Penal Pública que perfilan o dan forma a dicha demanda? En esta oportunidad, queremos identificar factores institucionales que inciden en la selectividad y en la activación de derechos. Partimos nuestro análisis indagando ¿qué atención existe en general, y específicamente en materia de violaciones a los derechos constitucionales y humanos causados por las condiciones de reclusión y la violencia intracarcelaria? Para el estudio recurrimos a información cuantitativa (análisis de estadísticas de la Defensa Penitenciaria) y cualitativa (entrevistas a actores claves). Constatamos que factores asociados a la estructura y a directrices organizacionales, como también a la práctica profesional de los defensores penitenciarios, coadyuvan para que las materias que atiende la Defensa Penitenciaria, terminen siendo un fiel reflejo de los indicadores y estándares predeterminados por la Defensoría Penal Pública, prestando menos importancia a situaciones como maltrato, tortura, violencia intracarcelaria y condiciones de vida inhumanas. Esta selectividad en la activación de derechos de los condenados atenta contra sus garantías constitucionales y, por ende, contra los objetivos institucionales de la propia Defensa Penitenciaria.

Palabras claves: Defensa penitenciaria; activación de derechos; ejecución penal; acceso a la justicia; defensa pública.

ABSTRACT: A decade ago, the Chilean Public Defense started a program of prison litigation. This article investigates institutional factors that may have an impact on the mobilization of the rights of persons deprived of their liberty. We wonder if the attention provided by the public service mirrors faithfully the demand for defense expressed by convicted persons, or if it responds to institutional policy decisions taken by the Public Defense office that outline or shape such demand? We are looking for institutional factors that determine the selectivity and activation of rights inside prisons. Our analysis starts describing the general public defense services provided to convicted prisoners, paying special attention to violations of constitutional and human rights caused by prison conditions and intra-prison violence. For our analysis, 
we used quantitative (statistics of the Prisoner Defense) and qualitative information (interviews with key actors). We found that factors associated with the organizational structure, as well as the professional practice of prison defenders, contribute to the fact that the matters handled by the Public Defense end up mirroring the indicators and standards predetermined by the Public Service, giving less importance to situations such as mistreatment, torture, intra-prison violence and inhumane living conditions. We conclude that this selectivity in mobilizing the rights of convicted prisoners violates their constitutional guarantees and, therefore, the institutional objectives of the Prison Defense Service itself.

KEYWORDS: public defense in prison affairs; mobilization of rights; inmate litigation; access to justice; public defense.

Sumario: Introducción. 1. Activación de derechos en el ámbito penitenciario. 2. Estudios previos sobre defensa penitenciaria. 3. Resultados del estudio. 3.1. Metodología. 3.2. Estructura organizacional de la Defensa Penitenciaria. 3.2.1. Equipo de atención y cobertura. 3.2.2. Funciones del defensor penitenciario y del coordinador regional. 3.3. Funcionamiento de la Defensa Penitenciaria: demanda y oferta de atención. 3.3.1. Solicitudes de atención y accesibilidad a los servicios de la DP. 3.3.2. Selección y asignación del defensor. 3.3.3. Cantidad de requerimientos. 3.3.4. Tipo de requerimientos. 3.3.5. Cumplimiento de requisitos. 4 . Conclusiones.

\section{INTRODUCCIÓN}

Hasta la época de la instalación del sistema procesal acusatorio en Chile (2000 a 2005$)^{5}$ no se concebía el ámbito penitenciario como propio de la jurisdicción. A pesar de varias iniciativas, que surgieron durante (1995) y después (2005) de la implementación de lo que iba a ser la "gran

5 Para un análisis de los desafíos pendientes de implementación de la reforma procesal penal en Chile, véase: ARELLANO, Jaime (Dir.) Desafíos de la Reforma Procesal Penal en Chile: análisis retrospectivo a más de una década. Santiago de Chile: CEJA JSCA, 2015. 
reforma de la justicia”, ningún intento de generar una ley de ejecución de la pena prosperó. ${ }^{6}$ Como reflejo de lo anterior, la preocupación por la situación de los condenados (especialmente los privados de libertad), sólo vino a manifestarse -de modo incipiente- en la Defensoría Penal hacia el año 2007, cuando el Defensor Nacional ${ }^{7}$ instruyó acerca de la obligación de los defensores de visitar a los condenados privados de libertad. ${ }^{8}$ Dos años más tarde (2009), surge la Defensa Penitenciaria chilena en una región del país y a partir de un programa piloto de la Defensoría Penal Pública. ${ }^{9}$ Tras otros dos años (2011) se pone en marcha el Modelo de Defensa Penitenciaria. ${ }^{10}$ Para ello, se externaliza el servicio de defensa a través de licitaciones. ${ }^{11} \mathrm{~A}$ su vez, se elabora un programa de implementación gradual del servicio, ampliando la atención ese año a dos regiones más. ${ }^{12}$ Cinco años más tarde (2016) se termina de instalar la Defensa Penitenciaria (en adelante DP) en todo el país.

6 STIPPEL analiza los distintos esfuerzos de modificación reglamentaria y de elaboración de una Ley de Ejecución de Penas en Chile. Véase: STIPPEL, Jörg. Cárcel, derecho y política. Santiago de Chile: LOM Ediciones, 2013, pp. 29 y ss.

7 Eduardo Sepúlveda ocupaba ese cargo desde abril 2006 a marzo 2008.

8 Oficio del $\mathrm{DN} \mathrm{N}^{\circ} 315$ de 17 de agosto de 2007 “Instruye sobre nuevas normas relativas a visitas de imputados condenados privados de libertad".

9 Chile tiene un total de 16 regiones. El programa comenzó en la Región de Coquimbo. Al inicio se financió con el apoyo de la Agencia Española de Cooperación Internacional para el Desarrollo (AECID) durante 9 meses. Con recursos propios de la Defensoría Penal Pública se logró financiar hasta un año y medio más del programa. Para una descripción detallada de los orígenes del proyecto, ver: SALINERO, M. Alicia. Programa de Defensa Penitenciaria: Una contribución al acceso a la justicia, Revista Debates Penitenciarios, CESC, Santiago, $N^{\circ} 19$, pp. 3-22, 2014. https://www.cesc.uchile.cl/debates_penitenciarios_19.pdf Acceso en: 27 en. 2019.

10 Resolución Exenta $N^{\circ} 2103$, del 01 de julio de 2011. Aprueba Modelo de Defensa Penal Pública Penitenciaria.

${ }^{11}$ El sistema de licitaciones se aplica a la defensa general en Chile desde el 2004. La Ley $N^{\circ} 19.718$ del año 2000, que crea la Defensoría Penal Pública, estableció un sistema de defensa mixto: un grupo de defensores institucionales, con régimen laboral de funcionarios públicos (de planta o a contrata) y otro grupo de defensores licitados, que se vinculan a la institución mediante un contrato de prestación de servicio seleccionado por un proceso de licitación pública al cuál postulan empresas prestadoras.

12 La Región del Biobío y la Región Metropolitana Sur. 
En el 2017, con la aprobación del "Manual de Actuaciones Mínimas para la Defensa Penitenciaria” (en adelante, MAM) ${ }^{13}$, la Defensoría Penal Pública buscó estandarizar la oferta en materia penitenciaria. La finalidad declarada de la normativa interna es "garantizar una defensa penal de calidad". ${ }^{14}$ El MAM establece las tareas que deben desarrollar los defensores penitenciarios y el "mínimo esperado de un defensor en dichas actuaciones". ${ }^{15}$ Recientemente (2019), se formuló la "Política de la Defensoría Penal Pública (en adelante, DPP) para la prestación de Defensa Penitenciaria”. ${ }^{16}$

Desde sus inicios, el objetivo principal de la DP ha sido "contribuir a mejorar la aplicación de las garantías constitucionales y el acceso a la justicia de los condenados privados de libertad". ${ }^{17}$

Al cumplirse una década del inicio de la DP chilena, nos interesa indagar -desde un enfoque sociojurídico- el rol que esta ha jugado en la activación de derechos en materia penitenciaria, es decir, en la posibilidad de hacer uso efectivo de un derecho y de emplear las instancias correspondientes para ello.

Siguiendo a Blankenburg, partimos de la idea que la activación ${ }^{18}$ de derechos depende de la interacción de la oferta de derechos y de la demanda de su ejercicio. ${ }^{19}$ El autor ubicaría a la Defensa Penitenciaria en el lado de "la oferta". Es desde esa perspectiva que nos proponemos estudiar el acceso a la justicia de las personas privadas de libertad. ${ }^{20}$

13 Resolución Exenta $N^{\circ} 219$, del 29 de mayo de 2017, del actual Defensor Nacional, Andrés Mahnke M.

14 Considerando 7, de la Resolución Exenta $N^{\circ} 219$, del 29 de mayo de 2017.

15 Presentación del MAM, Resolución Exenta N²19, del 29 de mayo de 2017.

16 Resolución Exenta N³56, del 17 de octubre de 2019.

17 Resolución Exenta No 2103, del 01 de julio de 2011. Aprueba Modelo de Defensa Penal Pública Penitenciaria.

18 BLANKENBURG habla de "Mobilisierung des Rechts", la traducción literal sería "movilización del derechos". Sin embargo, optamos por traducir el término como "activación" pues refleja de mejor forma el concepto empleado. Véase punto 2 del artículo.

19 BLANKENBURG, Erhard. Mobilisierung des Rechts. Eine Einführung in die Rechtssoziologie. Heidelberg: Springer Verlag. 1995, pp. 27 y 36.

20 FUCITO explica que "el tema del acceso a la justicia, desde el punto de vista sociológico, deriva de la confrontación entre las expectativas que surgen de 
Nos interesa saber ¿si la atención que brinda la Defensa Penitenciaria refleja sólo la demanda de defensa expresada por las personas condenadas, o si responde a decisiones de política institucional de la Defensa Penal Pública? Si fuese así, queremos identificar estos factores para entender cómo inciden en la práctica en la activación de los derechos de los condenados(as).

Nuestra hipótesis es que existe una selectividad en la activación de derechos, que se explica no sólo por la demanda de defensa por parte de los condenados, sino fundamentalmente por decisiones de política institucional de la DPP que perfilan o dan forma a dicha demanda. Entendemos que la DP debe ampliar las posibilidades de actuación y así de activación de derechos de las personas privadas de libertad. A su vez partimos del supuesto que la decisión misma sobre si se activa o no un derecho, siempre debería depender del sujeto interesado y afectado, en este caso, del condenado(a).

Para ello, indagamos en las materias que constituyen el fondo de las solicitudes de atención (la demanda). Luego analizamos algunos factores institucionales que podrían estar incidiendo en el tipo y magnitud de dicha demanda, vinculados con directrices institucionales de la DPP, la estructura organizacional de la DP y la práctica de atención de los defensores penitenciarios.

En nuestro análisis no nos detenemos en las deficiencias de la oferta a nivel normativo ${ }^{21}$, como la falta de una Ley de Ejecución de Penas. ${ }^{22}$

la ley y las condiciones reales de tal acceso, y de la supuesta defensa”. Argumenta que "las posibilidades desiguales para litigar constituyen un tema que interesa a toda la sociología jurídica, en cuanto muestra una ruptura entre la declaración formal de un derecho y su alcance real". FUCITO, Felipe. Sociología del Derecho. El orden jurídico y sus condicionantes sociales. Buenos Aires: Editorial Universidad, 1999, p. 287 y ss.

Coincidimos con la afirmación de BOVINO, al señalar que la cárcel nunca ha sido un "espacio sin ley", sino un ámbito de inobservancia generalizada de la misma. BOVINO, Alberto. Control judicial de la privación de libertad y derechos humanos. Revista Jurídica, $\mathrm{N}^{\circ}$ 17, pp. 1-23, 2004. p. 1. Disponible en: https://www.revistajuridicaonline.com/2004/01/el-control-judicial-de -la-privacion-de-libertad-y-derechos-humanos/ Acceso en: 27 en. 2019.

22 Para un análisis sobre el tema, véase: STIPPEL, Jörg. Cárcel, derecho y política. Santiago: LOM Ediciones, 2013, pp. 29 y ss. 
Ni profundizamos sobre aspectos de la cultura jurídica chilena. ${ }^{23}$ Tampoco analizamos en detalle problemas en la generación de la "demanda" de derechos y servicios jurídicos, que depende -entre otros- de la percepción que tienen los condenados de sus derechos y de la posibilidad real de su activación. Muchas personas privadas de libertad no activan sus derechos pues temen sufrir represalias, porque normalizan situaciones de vulneración o porque desconfían de la efectividad de los mecanismos legales. Ello impacta en la percepción subjetiva de la utilidad del derecho como mecanismo de resolución de conflictos, teniendo como resultado una demanda baja. ${ }^{24}$

En la primera parte de este artículo, desarrollamos algunos planteamientos teóricos sobre la concepción de la activación de derechos y los factores involucrados. En la segunda parte, revisamos estudios previos sobre el tema a nivel nacional. A partir de estos, enmarcamos el análisis empírico que realizamos en la tercera parte. Allí exponemos la metodología y los resultados de investigación. Concluimos nuestro trabajo con los principales hallazgos y algunas recomendaciones de política criminal.

23 PÉREZ-PERDOMO explica que: "La noción de cultura jurídica requiere situar la comprensión del derecho en su contexto social y político, admitiendo que una parte importante de ese contexto está conformada por los valores, actitudes y opiniones de las personas en relación con el derecho". PÉREZ -PERDOMO, Rogelio. Versión escrita de la conferencia pronunciada por el galardonado al recibir el Premio Internacional de Investigación en Derecho "Héctor Fix-Zamudio" 2014. "El derecho comparado y la comparación de culturas jurídicas. Una perspectiva latinoamericana". Boletín Mexicano de Derecho Comparado, año XLIX, N 146 , pp. 477-504, 2016, Disponible en: https://revistas.juridicas.unam.mx/index.php/derecho-comparado/issue/ view/537 Acceso en: 27 en. 2019, p. 492.

${ }^{24}$ FUCITO, Felipe argumenta que "las regularidades que aparecen en la investigación empírica son claras en cuanto a que la litigiosidad decrece con el nivel económico, por ignorancia del derecho, por la alienación del mundo jurídico que sufren las clases bajas, que las desalienta a iniciar acciones aun cuando crean que han sido vulnerados sus derechos reconocidos, así como una difusa sensación de temor y represalias por hacerlo". Véace FUCITO, Felipe. Sociología del Derecho. El orden jurídico y sus condicionantes sociales. Buenos Aires: Editorial Universidad, 1999, p. 289. También STIPPEL, Jörg. Las cárceles y la búsqueda de una política criminal para Chile. Santiago: LOM Ediciones, 2006, pp. 190-192. 


\section{ACTIVACIÓN DE DERECHOS EN EL ÁMBITO PENITENCIARIO}

Cuando nos referiremos a la activación de derechos, aludimos al ejercicio de los mismos y al empleo de las instancias correspondientes para ello. Para nuestro análisis nos apoyamos en las ideas de Blankenburg. El sociólogo alemán argumenta que la activación de los derechos depende de factores asociados tanto a la oferta como a la demanda. Del lado de la “oferta”, el autor sitúa a las normas jurídicas, que definen las situaciones problemáticas o conflictos sobre los cuales se pueden presentar reclamos. ${ }^{25}$ También forman parte de la oferta las instituciones y servicios de asistencia jurídica que viabilizan dichas reclamaciones. Por el lado de la "demanda", se encuentra la percepción (o conciencia de derechos) de las personas afectadas y sus expectativas respecto a la posibilidad real de su reclamación.

Blankenburg afirma que se requiere de actores para convertir un problema o conflicto social en un problema legal. Existe entonces una interacción de la oferta de derechos y de la demanda de su ejercicio. ${ }^{26} \mathrm{~A}$ su vez argumenta, que para que la oferta de derechos sea efectiva, debe ser posible movilizarla de facto. ${ }^{27}$

25 Legalmente la persona privada de libertad "se encuentra en una relación de derecho público con el Estado, de manera que fuera de los derechos perdidos o limitados por su detención, prisión preventiva o condena, su condición jurídica es idéntica a la de los ciudadanos libres" (Art. 2 del Reglamento Penitenciario, DS 518). Mañalich entiende esta regla como "una especificación del alcance del principio de legalidad de la sanción penal, en términos de una exigencia de su ejecución con estricta sujeción a ley: nulla poena sine lege stricta". MAÑALICH, Juan Pablo. El derecho penitenciario entre la ciudadanía y los derechos humanos. Revista Derecho y Humanidades, n. 18, pp. 163178, 2011. Por su parte, HORVITZ explica que "Tratándose de la regulación de los derechos constitucionales de los reclusos, no afectados directamente por la pena, se impone el principio de reserva de ley y su tutela efectiva a través de un órgano jurisdiccional exclusivo, dadas las condiciones de encierro de los titulares de tales derechos y la necesidad de mecanismos expeditos de protección, especialmente frente a abusos de la propia administración penitenciaria." HORVITZ, M. Inés. La insostenible situación de la ejecución de las penas privativas de libertad: ¿vigencia del Estado de derecho o estado de naturaleza? Revista Política Criminal, Santiago de Chile, v. 13, n 26, pp. 904951, 2018. p. 925.

BLANKENBURG, Erhard. Op. cit. pp. 27 y 36.

Ibídem, p. 30. 
Sabemos que, si una persona decide activar sus derechos desde la cárcel, enfrenta múltiples obstáculos. ${ }^{28}$ Debido a la situación de encierro, es obvio que no puede dirigirse a una oficina de abogados para pedir apoyo. Tampoco puede simplemente llamar a un defensor, pues existen restricciones legales o arbitrarias que dificultan el acceso a un teléfono. En consecuencia, las personas privadas de libertad muchas veces dependen de terceros mensajeros, familiares o funcionarios del sistema penitenciario. ${ }^{29}$ Tienen que confiar en que ellos les ayuden en la activación de sus derechos.

Blankenburg señala, que la demanda por asesoramiento jurídico para determinadas situaciones problemáticas, no es independiente de la oferta de asesoramiento jurídico que exista. Por el contrario, esta demanda se desencadena justo por la oferta definida por las instituciones de asesoramiento. Blankenburg se refiere en su análisis a instituciones en Inglaterra (law centers), Holanda (rechtswinkels) y Estados Unidos (neighborhood legal services). Estas instituciones prestan asesoramiento jurídico en materias relacionadas al arriendo de viviendas y otros temas, principalmente a personas de escasos recursos. El sociólogo resalta que la labor de estas organizaciones siempre está subsidiada. Por ello, sus decisiones respecto a aceptar o no un caso, no son en base a los honorarios que esto generaría, sino en función de la evaluación de si el caso entra en la categoría de asuntos que ellos apoyan. No se guían únicamente por las necesidades no satisfechas, sino que establecen sus propios criterios para lo que consideran necesidades importantes. ${ }^{30}$

En otro trabajo, Blankenburg y Bruinsma explican que las partes y sus abogados invocan a los tribunales y por lo tanto determinan su carga laboral (input). En base a ello el poder judicial produce los resultados (output). Pero los abogados también buscan alternativas al litigio. Evalúan las posibilidades de éxito de su cliente, los costos, la capacidad de los tribunales y el tiempo que toman los procedimientos. A menudo estos

28 Esto ocurre en general, pero será más relevante si se trata de derechos de los cuales no se ha hecho cargo la institución y/o respecto de los que no existe una adecuada regulación jurídica.

29 STIPPEL muestra que, entre el 2000 y 2002, la mayor parte de los recursos de protección y amparo en favor de personas privadas de libertad, fueron presentados por familiares de estas (56,6\%). STIPPEL, Jörg. Op. cit. p. 201.

BLANKENBURG, Erhard. Op. cit. pp. 28 a 30 
factores inducen a los abogados y a sus clientes a buscar foros alternativos de resolución de conflictos. En este sentido, concluyen que la oferta de tribunales rápidos y accesibles, y la demanda de derechos (litigios) son mutuamente dependientes. ${ }^{31}$ Mientras más rápidos y accesibles sean los tribunales, más derechos se van a activar por esta vía. ${ }^{32}$ Los autores afirman, por lo tanto, que los códigos de derecho no determinan lo que hacen los abogados, pues entre la legislación y su aplicación se encuentra la profesión jurídica que ejerce su propio poder de definir lo que debe ser válido en la ley. ${ }^{33}$ En adelante vamos a ver hasta qué punto los planteamientos de estos autores tienen su reflejo en la práctica de la Defensa Penitenciaria chilena.

\section{ESTUDIOS PREVIOS SOBRE DEFENSA PENITENCIARIA}

En Chile, uno de los primeros estudios que analiza el tema de la defensa penitenciaria desde la perspectiva de la activación de derechos, fue desarrollado por Stippel en 2006. Demuestra que, luego de implementada la Reforma Procesal Penal en Chile (2000-2005), los defensores públicos habían conseguido logros principalmente "respecto a los imputados, dejando relegada la protección de los condenados". ${ }^{34}$

Un trabajo más reciente de Libedinsky analiza la Defensa Penitenciaria chilena desde una perspectiva de gestión. Ella sugiere mejorar la coordinación entre las distintas instituciones involucradas. Argumenta que "al estar el tema penitenciario muy sujeto a la discrecionalidad de

\footnotetext{
31 BLANKENBURG, Erhard y BRUINSMA, Freek. The role of courts in the Netherlands and Germany- Dutch Legal Culture Compared. En: GESSNER Volkmar; HOELAND Armin y VARGA Csaba (Eds.). European Legal Cultures. Aldershot: Dartmouth, pp. 344 a 352, 1996, p. 346.

32 FEEST también describe como la creación de una judicatura especializada en ejecución de penas lleva a una "explosión de la demanda de derechos en materia penitenciaria en Alemania”. Véase: FEEST, Johannes. Elaboración y contenido de la ley penitenciaria y su impacto en el sistema penitenciario alemán. Revista de Estudios Criminológicos y Penitenciarios, Santiago de Chile, N 7. Gendarmería de Chile/UNICRIM, pp. 17 - 28, 2005. p. 18.

33 BLANKENBURG, Erhard y BRUINSMA, Freek. Op. cit. p. 345.

34 STIPPEL, Jörg. Op. cit. p. 258.
} 
Gendarmería ${ }^{35}$, solo por medio de coordinaciones entre esta institución y la DPP, se pueden establecer determinados protocolos de trabajo y de operación que permitan implementar este programa de manera exitosa". ${ }^{36}$ También se refiere a la labor de la defensa licitada. Sugiere que deben "generarse mecanismos que permitan a la Defensoría controlar la labor de los abogados, no solo en base a la información que ellos mismos otorgan, sino también en relación a la información que puedan generar las mismas Defensorías Regionales, los usuarios del Programa de DP, así como el Poder Judicial y Gendarmería”. ${ }^{37}$

Aparte de estas investigaciones, la DPP ha encargado varias auditorías externas. Un informe de la Universidad de Chile (2017) analiza el Programa de Licitaciones de Defensa Penal Pública, y en particular evalúa la DP. Afirma que "la naturaleza de la defensa penitenciaria es en esencia menos regular que la defensa general, por cuánto su demanda rara vez es espontánea" ${ }^{38}$ Otra auditoría más reciente analizó las actuaciones mínimas de la DP (2019). El objetivo fue determinar el nivel de cumplimiento de los estándares de defensa técnica consignados en el MAM, por el equipo de defensa penitenciaria en siete Defensorías Regionales del país. Encontraron que, a nivel nacional, el 73,2\% (año 2018) de los requerimientos tramitados

35 Gendarmería de Chile es la institución a cargo de la administración de los recintos penitenciarios.

36 LIBEDINSKY, Sofía. Rediseño del Modelo de Defensa Penitenciaria para Adultos Privados de Libertad en el nuevo Sistema Procesal Penal. Revista Estudios de Políticas Públicas, Vol. 1, pp. 226-245, 2016. pp. 242 y ss. Disponible en: https://www.researchgate.net/publication/292347188_Rediseno_del_ modelo_de_defensa_penitenciaria_para_adultos_privados_de_libertad_en_ el_nuevo_sistema_procesal_penal Acceso en: 15 agosto, 2019. Ibídem, p. 244.

CENTRO DE SISTEMAS PÚBLICOS. Departamento de Ingeniería Industrial, Facultad de Ciencias Físicas y Matemáticas, Universidad de Chile. Evaluación del Programa de Licitaciones de Defensa Penal Pública de la Defensoría Penal Pública. Informe Final. 2017. Disponible en: http://www.sistemaspublicos. cl/wp-content/uploads/2018/07/DIPRES-DPP-Informe-Final.pdf

Acceso en: 20 agosto, 2019. Encontraron que, entre 2014 y 2016, "en promedio, los defensores penitenciarios tendrían 10 audiencias al mes, 39 estudios de requerimientos y registrarían actividades 59 veces al mes", p. 70 . En cuanto al salario, calculan que la hora de atención por defensa penitenciaria tiene un precio promedio de $\$ 18.055$ pesos chilenos (USD 23 aproximadamente), pp. 72 y ss. y tabla 39. 
por los defensores penitenciarios puede clasificarse como administrativos, siendo los restantes de tipo judicial. ${ }^{39}$

Vemos que, en los últimos años, el derecho penitenciario y la protección jurídica de las personas privadas de libertad ha ganado mayor espacio en la academia chilena. Existen artículos ${ }^{40}$ y libros que se dedican a la temática carcelaria. ${ }^{41}$ Otras publicaciones analizan la evolución histórica del sistema penitenciario chileno ${ }^{42}$ y algunos la

39 CENTRO DE ESTUDIOS JUSTICIA Y SOCIEDAD. Instituto de Sociología de la P. Universidad Católica de Chile (2019). Auditoría Externa de Actuaciones Mínimas para la Defensa Penitenciaria 2018-2019. Disponible en: http:// www.dpp.cl/resources/upload/efb3ac4f6a04a85caa2d0e898bf28f05.pdf Acceso en: 16 ago. 2019, p. 27. No obstante, relativizan el resultado, pues "hay algunos requerimientos que pueden ser considerados tanto administrativos como judiciales, dependiendo del momento y de las gestiones vinculadas. Estiman, que por esto "la descripción realizada de los requerimientos según estas categorías puede ser poco clara o explicativa de lo que realmente se está haciendo en la práctica de defensa penitenciaria”, p. 28.

Aquí podemos mencionar los artículos de HORVITZ, M. Inés. La insostenible situación de la ejecución de las penas privativas de libertad: ¿vigencia del Estado de derecho o estado de naturaleza? Revista Política Criminal, Santiago de Chile, v. 13, n 26, pp. 904-951, 2018 http://dx.doi.org/10.4067/S071833992018000200904; CARNEVALI, Raúl y MALDONADO, Francisco. El tratamiento penitenciario en Chile. Especial atención a problemas de constitucionalidad. Revista Ius et Praxis, año 19, n. 2, pp. 385 - 418, 2013. Disponible en: https://scielo.conicyt.cl/pdf/iusetp/v19n2/art12.pdf Acceso en: 16 jun. 2020; CASTRO, Álvaro. Estándares de la Corte Interamericana de Derechos Humanos en materia de imputados y condenados privados de libertad. Anuario de Derechos Humanos, n. 14, pp. 35-54, 2018. Disponible en: https://revistas.uchile.cl/index.php/ADH/article/download/49161/54183/ Acceso en: 16 jun. 2020.

41 Entre ellos: FERNÁNDEZ, Marco Antonio. Derecho penitenciario chileno. Problemas en torno a su naturaleza jurídica. Santiago de Chile: Hammurabi, 2019; CESANO, José. Derecho Penitenciario: Aproximación a sus Fundamentos. Córdova: Alveroni Ediciones, 2009; CONTESSE, Javier y CONTRERAS, Lautaro (eds.). La insostenible situación de las cárceles en Chile: debate sobre la prisión y los derechos humanos. Santiago: Editorial Jurídica de Chile, 2019; CALDERÓN, Rodrigo. Delincuencia, Políticas de estado y derechos humanos-a propósito de la cuestión penitenciaria en Chile. Santiago de Chile; RIL Editores, 2015; LEÓN, Marco Antonio. Encierro y Corrección. La Configuración de un Sistema de Prisiones en Chile (1800 - 1911) Tomo II. y III. Santiago de Chile: Universidad Central de Chile, 2003.

42 Aquí destacan los trabajos de LEÓN, Marco Antonio. Encierro y Corrección. La Configuración de un Sistema de Prisiones en Chile (1800 - 1911) Tomo II. y III. 
protección jurídica en las cárceles chilenas. ${ }^{43}$ Sin embargo, aún faltan estudios sobre la activación de derechos en el contexto de la defensa penitenciaria.

\section{RESULTADOS DEL ESTUDIO}

\subsection{Metodología}

En nuestro trabajo, utilizamos una metodología de tipo mixta: cuantitativa y cualitativa. Los datos cuantitativos provienen de la base de datos (Sistema Informático de Gestión de Defensa Penal, en adelante SIGDP) de la DPP. ${ }^{44}$ Todos los defensores penitenciarios están obligados a registrar sus actuaciones dentro de plazos pre-establecidos en esta base.$^{45}$ Los datos fueron sometidos a un análisis descriptivo, a través del cálculo de frecuencias, porcentajes y promedios. A partir de ello se elaboraron las respectivas tablas de contingencia para mostrar los resultados. La información cualitativa proviene de entrevistas semiestructuradas realizadas a actores claves. ${ }^{46} \mathrm{El}$ contexto

Santiago de Chile: Universidad Central de Chile, 2003.

43 INSTITUTO NACIONAL DE DERECHOS HUMANOS. Informe anual 2012. Disponible en: http://www.indh.cl/wp-content/uploads/2012/12/Inf-Anual-INDH12-WEB.pdf p. 98; Acceso en: 28 de junio de 2020; STIPPEL, Jörg. Cárcel, derecho y política. Santiago: LOM Ediciones, 2013, GÓMEZ, Gastón. Derechos Fundamentales y Recurso de Protección. Santiago de Chile: Universidad Diego Portales, 2005; KENDALL, Stephan. Tutela judicial efectiva en la relación jurídica penitenciaria. Santiago de Chile: Librotecnia, 2010.

${ }^{44}$ Obtenida en base a un Convenio Marco de Cooperación Interinstitucional entre la Universidad Central de Chile y la Defensoría Penal Pública, 05 de enero de 2017.

45 Estudios previos han mostrado que la calidad de registro de la información varía. La P. Universidad Católica encontró que "los datos de los requerimientos y sus gestiones están en promedio menos presentes en las carpetas $(30,1 \%)$ que en el SIGDP $(59,7 \%)$, mostrando que la plataforma digital suele ser un mejor mecanismo para hacer el seguimiento de los avances del requerimiento". Tabla $\mathrm{N}^{\circ} 32$, p. 66.

46 Se entrevistó a Alicia Salinero, primera Coordinadora Nacional del Programa de Defensa Penitenciaria (2009 al 2013). También a 4 defensores penitenciarios de la Región Metropolitana. Todos firmaron un consentimiento 
del análisis de los datos, lo constituyen las distintas resoluciones internas de la DPP.

\subsection{Estructura organizacional de la Defensa Penitenciaria}

Nos interesa saber cómo la estructura organizacional y la definición de los distintos roles dentro de la DP podría estar incidiendo tanto en la oferta del servicio de defensa, como en la configuración de la propia demanda que recibe.

La atención en materia penitenciaria se realiza a través de un equipo conformado por abogados(as) y trabajadores(as) sociales. Actualmente (2020) a nivel nacional el equipo penitenciario cuenta con 54 defensores, 42 trabajadores sociales, 1 psicóloga y 30 asistentes administrativos. La competencia de los defensores está dada por el recinto penal (y no por el tribunal). Así, los requerimientos de los privados de libertad de una cárcel determinada son tramitados por el mismo equipo, aun cuando deban presentarse en tribunales de otras comunas. Aparte de los defensores penitenciarios, existe a nivel regional la figura del coordinador, sus tareas se encuentran descritas ${ }^{47}$, pero en la práctica -como veremos- no existe claridad acerca de sus funciones.

Si nos detenemos en la información cuantitativa, podemos observar la evolución de la cantidad de personas privadas de libertad atendidas por estos equipos en la siguiente tabla.

informado para garantizar las implicancias éticas de la investigación. Las entrevistas fueron transcritas y sometidas a un análisis de contenido. La investigación contó con la aprobación del Comité de Ética de la Universidad Central de Chile, según consta en carta del 05.12.2016 de parte del Presidente del Comité de Ética, Arturo Millán Fuentes. Proyecto Código CIP16018. Universidad Central de Chile.

47 Resolución Exenta No 2103, del 01 de julio de 2011. Aprueba Modelo de Defensa Penal Pública Penitenciaria. 
TABLA Nº 1. Evolución del porcentaje de población condenada privada de libertad atendida por la Defensa Penitenciaria ${ }^{48}$

\begin{tabular}{|c|c|c|c|c|c|c|}
\hline $\mathrm{N}^{\circ} /$ Año & 2013 & 2014 & 2015 & 2016 & 2017 & 2018 \\
\hline $\begin{array}{c}\mathrm{N}^{\circ} \text { personas privadas de } \\
\text { libertad potencialmente } \\
\text { beneficiarias de atención }\end{array}$ & 74203 & 71713 & 71728 & 71718 & 70701 & 74066 \\
\hline $\mathrm{N}^{\circ}$ personas atendidas & 5.943 & 10.184 & 12.708 & 15.611 & 16.575 & 18.800 \\
\hline $\begin{array}{c}\text { Porcentaje de personas } \\
\text { atendidas de la población } \\
\text { beneficiaria potencial }\end{array}$ & 8,0 & 14,2 & 17,7 & 21,8 & 23,4 & 25,4 \\
\hline
\end{tabular}

Fuente: Elaboración propia en base a datos del SIGDP y Compendios Estadísticos de Gendarmería de Chile, disponibles en: https://www.gendarmeria.gob.cl/estadisticas_compendios.html

Vemos que esta cifra se ha ido incrementando sistemáticamente, a la par de la instalación paulatina que tuvo la DP a lo largo del país. Sin embargo, durante los años 2017 y 2018, con la DP ya implementada en todo el país, la cobertura de atención no alcanza ni la tercera parte del total de los posibles usuarios (23,4\% en el 2017 y $25,4 \%$ en 2018 ).

Ese nivel de cobertura puede tener varias explicaciones. Por un lado, puede existir un porcentaje de condenados que recurren a los servicios de defensores privados, ya sea por desconfianza en los servicios de la DP, la esperanza de una mejor atención o el desconocimiento de sus servicios. No obstante, considerando la situación socio-económica de la mayoría de los condenados, parece poco probable que este porcentaje pueda ser significativo. Otra explicación que parece más convicente, en base a las entrevistas realizadas a los defensores penitenciarios, es que

48 La cifra que refleja con mayor precisión la población potencial usuaria de la DP, corresponde a la población condenada privada de libertad atendida por Gendarmería de Chile, es decir, aquella compuesta por la población vigente al último día del año anterior y el total de ingresos del año correspondiente. Sin contabilizar imputados, detenidos ni procesados por el sistema antiguo. Cabe señalar que esta cifra es mayor que la población penal "vigente" y la población "promedio", que osciló en el rango de 40.000 a 45.000 personas a nivel nacional en cada uno de esos años. 
la cifra es reflejo de una insuficiente cantidad de defensores respecto al número de usuarios potenciales.

Si en los años 2017 y 2018 se contaba con un total a nivel nacional de 55 defensores penitenciarios, esto significa que cada defensor atendió en promedio a 301 personas el 2017 y a 341 el año $2018 .^{49}$

En las entrevistas realizadas, los defensores penitenciarios fueron enfáticos en señalar la gran carga laboral que tienen, así como las diferencias que existen entre los diferentes penales y cómo eso repercute en las posibilidades de atención: "En nuestra cárcel que son casi cinco mil internos ${ }^{50}$, somos siete defensores penitenciarios, o sea, nosotros al final nos reventamos y vulneramos nuestros derechos en protección de los derechos de los condenados, hay un montón de cosas que no se pueden hacer y uno podría hacer un trabajo mucho más profundo, de calidad y mucho más rápido (...) pero el sistema es bien perverso, no lo permite. Somos muy pocos defensores, no hay presupuesto”. (DP 1). ${ }^{51}$ Otro de los defensores ratifica esto y alude a las diferencias entre recintos penitenciarios: "Somos tan pocos defensores para tanta población penal que no llegamos a todos, es imposible (...). Pero esta conversación sería súper distinta si tú la tuvieras con la defensora de la cárcel de Talagante ${ }^{52}$, porque es un número de internos muy reducido y sí se puede abarcar a toda la cárcel. Por ejemplo, en Puente Alto $^{53}$ (...) todas las libertades condicionales la tomaba la DP, todas, ni un defensor privado. En cambio,

49 En los años 2017 y 2018 se contaba con 55 defensores penitenciarios, actualmente son 54. Por otra parte, la cantidad de personas atendidas no se distribuye de manera homogénea entre los defensores, ya que algunos centros penitenciarios tienen una población penal significativamente mayor.

50 Se refiere al Centro Penitenciario Santiago Sur, conocido como "Ex Penitenciaría”, cuya población penal es de 4.859 personas (diciembre, 2019). Ver: https://www.gendarmeria.gob.cl/estadisticaspp.html

51 Para fines de identificación, utilizaremos las siglas DP (Defensor Penitenciario) y los números respectivos del 1 al 4, según a quién corresponda la cita.

52 El Centro Penitenciario de Talagante, tiene una población penal de 230 personas (diciembre, 2019).

53 El Centro Penitenciario de Puente Alto tiene una población penal de 1.207 personas (diciembre, 2019). 
en Colina ${ }^{54}$, en Santiago Sur, no daríamos abasto, estaríamos todo el día en la corte". (DP 4).

Los defensores criticaron también lo que perciben como una falta de claridad acerca de las funciones del coordinador regional. Afirman que "tampoco sabemos qué tiene que hacer el coordinador. No está establecido" (DP 4). Afirman que "no es jefatura y, además, no es un coordinador que sea exclusivo de la DP. Es un coordinador que ve todo" (DP 1). Por ello perciben que es "un problema más estructural, que la Defensoría no ha prestado ni los recursos, ni la importancia a la DP, siempre se ha minimizado, hemos estado ahí en las sombras, no se sabe muy bien lo que hacemos y sobretodo el tema de recursos" (DP 1). Sienten que en muchas materias faltan "directrices que debiesen venir de la regional" (DP 4).

Estas opiniones permiten visibilizar cómo decisiones institucionales (el número de defensores asignados a un centro penitenciario y la falta de directrices desde los coordinadores regionales) impactan en la oferta de servicios jurídicos de defensa. Eso implica también, que existe una demanda desatendida de derechos, cuya activación no es respaldada por el sistema de prestación del servicio de la DP.

\subsection{Práctica de atención de la Defensa Penitenciaria: demanda y oferta DE ATENCIÓN}

A continuación, analizamos el funcionamiento práctico de la DP. Nos interesa saber cómo perfila o da forma a su demanda y así a la activación de derechos.

\subsubsection{SOlICITUDES DE ATENCIÓN Y ACCESIBILIDAD A LOS SERVICIOS DE LA DP}

La atención del equipo que presta la DP tiene su punto de partida en las solicitudes de atención. ${ }^{55}$ Cuando la solicitud es recibida por el

54 En la comuna de Colina hay dos recintos penitenciarios: Colina I, que tiene una población penal de 2.024 personas (diciembre, 2019) y Colina II, con 1.824 personas (diciembre, 2019).

55 El MAM las define como "aquellas cuestiones concretas que demandan los internos y que se traducen en solicitudes que realiza el programa de defensa 
equipo de la Defensoría, debe ser ingresada al sistema informático a la brevedad posible. En el caso de ser una solicitud escrita, ese ingreso debe efectuarse dentro de las 24 horas posteriores a la recepción. ${ }^{56}$ En base a las cifras registradas en el SIGDP, podemos apreciar que ha existido un incremento sistemático en el tiempo de la cantidad de solicitudes de atención. En el año 2012, estas fueron 4.284; en el 2016 -con la DP instalada en todo el país, la cifra llegó a 16.899 solicitudes de atención.

TABLA N² 2. Evolución de la cantidad de solicitudes de atención

\begin{tabular}{|c|c|c|c|c|c|c|c|}
\hline $\mathrm{N}^{\circ} /$ Año & 2012 & 2013 & 2014 & 2015 & 2016 & 2017 & 2018 \\
\hline $\begin{array}{c}\mathrm{N}^{\circ} \text { de Solicitudes } \\
\text { de atención }\end{array}$ & 4.284 & 6.327 & 9.687 & 11.693 & 16.899 & 19.451 & 23.845 \\
\hline
\end{tabular}

Fuente: Elaboración propia en base a datos del SIGDP.

El aumento sostenido en el tiempo se explica, primero, por el proceso de instalación paulatino. Pero también vemos un incremento considerable en el número de solicitudes posterior al año 2016, ya que solo entre el 2017 y el 2018 se observa un 23\% de aumento. Eso se podría explicar por el mayor conocimiento de este servicio por parte de los privados de libertad. Sin embargo, pese a este aumento, los defensores identifican una serie de dificultades que afectan la posibilidad de activación de derechos. Afirman que: "Muchas solicitudes llegan cuando uno va a hacer visita carcelaria (...) Los mismos internos se van recomendando,

penitenciaria directamente ante la autoridad administrativa (...) o ante la autoridad judicial". Sorprende el lenguaje utilizado por el MAM. Si partimos desde los objetivos de la DP, podemos entender que el reclamo de derechos constitucionales y el acceso a la justicia se convierten en "aquellas cuestiones concretas que demandan los internos". Pero hablar de "cuestiones concretas" no es lo mismo que hablar de derechos subjetivos contra cuya violación se inician acciones legales. A su vez, son los internos los que "demandan", es la ley que impone los imperativos. Si bien existen también gestiones que no afectan directamente derechos subjetivos, como obtener copias de determinados documentos, la finalidad de su consecución se relaciona a ellos. Véase Capítulo I, numeral 2 e. del MAM.

Capítulo I, numeral 1 del MAM. 
se pasan el dato, nos pasan papeles de sus amigos o también pasa que a uno le va bien con algo y se hace un poquito famoso" (DP 4). También relatan que la forma cómo llegan las solicitudes depende de la unidad penal. En una de ellas (Puente Alto) "uno entrega una lista a un $\mathrm{mozo}^{57}$, que es como el encargado, y él llama a todos los internos de la torre y por lo general ahí bajan todos". Sin embargo, hace notar que "de repente se pierden los papeles". Depende, por ello, "de la proactividad del interno encargado de llamar, de entregar los papeles, del mozo. Si el mozo no quiere hacer su trabajo, uno le entrega el papel, él rompe los papeles y listo, ¿y el interno? 'no, no quiso salir" (DP 4). Otra defensora hace notar que en el Centro Santiago Sur "no es fácil que los presos lleguen a dónde nosotros entrevistamos. No es fácil porque son casi cinco mil personas y el único motivo por el cual las personas pueden llegar ahí es porque los llamó un abogado o lo llamó una técnica de clasificación estadística" (DP 3). También reciben solicitudes cuando los presos van al hospital pues "en el hospital tienen ingreso por otro lado y de repente cuando van a enfermería, se arrancan. Ahí los retan y los quieren devolver a punta de golpes y, por lo tanto, de repente muchos internos llegan y te dicen "por favor, yo alcancé a pasar ¿puede llamar a tres personas que no alcanzaron a pasar?" (DP 3). Otro defensor agrega que "los internos mientras más información tienen de cosas que se pueden ir haciendo, como impugnar sanciones o que el procedimiento no se cumplió, cada vez van requiriendo más defensa penitenciaria” (DP 4).

Vemos que la cantidad de solicitudes recibidas por la DP no depende sólo de la necesidad y motivación de los condenados. La accesibilidad a los defensores es clave y no constituye un proceso regular o institucionalizado. Tampoco se observa un entrelazamiento adecuado entre la DP y los procesos institucionales de Gendarmería de Chile. La posibilidad de conseguir apoyo en la activación de derechos queda entregada a la buena voluntad de los funcionarios penitenciarios, a la decisión de otros presos, al acceso a las oficinas de la DP, a las condiciones particulares de cada unidad penal y a la difusión que se realice de la oferta de atención.

57 "Mozo" se le denomina en las cárceles chilenas a los internos que colaboran con Gendarmería de Chile en servicios de aseo, alimentación y mantención de los establecimientos penitenciarios. 


\subsubsection{SELECCIÓN Y ASIGNACIÓN DEL DEFENSOR PENITENCIARIO}

Ante la solicitud de atención, un defensor(a) penitenciario tiene que ser asignado(a) al caso. La elección del defensor no es libre. El instructivo correspondiente estipula que la asignación se realiza "por el coordinador de la respectiva empresa" o el Coordinador Regional de la Defensa Pública según criterios de derivación previamente establecidos. El instructivo no contempla normas acerca del derecho de los condenados de elegir a su defensor, ni se establecen mecanismos para resolver posibles conflictos que se puedan generar entre el defendido y su defensor. Si bien la normativa que crea a la Defensoría regula que el imputado puede elegir de la nómina elaborada por la respectiva Defensoría Regional a su defensor ${ }^{58}$, en materia penitenciaria esta decisión, como regla, es tomada por el coordinador de la respectiva empresa licitada. Las bases de licitación tampoco se refieren directamente a la necesaria confianza entre el condenado y su defensor. ${ }^{59}$ Sólo estipulan el deber de "respetar la voluntad del condenado". ${ }^{60}$ Observamos, además, que se le debería informar al condenado durante la primera entrevista sobre su derecho de solicitar

58 Artículos $\mathrm{N}^{\circ} 51$ y N 52 de la Ley $\mathrm{N}^{\circ} 19.718$.

59 Respecto al contenido mínimo de la primera entrevista, el MAM tampoco hace referencia a la necesidad de establecer lazos de confianza con el defendido. Solo menciona la posibilidad del condenado de rechazar voluntariamente la primera entrevista (Capítulo I, numeral 2 letra. f.). No da la oportunidad de solicitar que esta se realice con otro defensor. Además, si el condenado rechaza la atención, el MAM le obliga a firmar una constancia ("debiendo el privado de libertad firmar"). Esta además debe contar con la firma del funcionario encargado (Capítulo I, numeral 2 letra. f. del MAM). Si bien es entendible exigir la firma del condenado para tener evidencia que fue él quien rechazó la atención, es difícil imaginar como un defensor le pueda obligar a firmar tal constancia. Vemos como los intereses institucionales se imponen en desmedro de los derechos de los condenados.

60 Resolución $\mathrm{N}^{\circ}$ 131, del 30 de septiembre de 2014. Formaliza acuerdo del Consejo de Licitaciones de defensa penal pública; Fija nuevo texto refundido de las bases administrativas y técnicas generales y anexos para la licitación pública del "Servicio de defensa penal de personas condenadas"; y establece lo que indica. Disponible en: http://www.dpp.cl/resources/upload/ 4827c3e5502e7f8081b0a3c42c03ce67.pdf Acceso en: 20 marzo, 2020. Punto 8.4.A, letra c., p. 26. 
en cualquier momento, con un fundamento plausible, el cambio de su defensor ${ }^{61}$ No obstante, ni la ficha elaborada para la primera entrevista, ni tampoco el $\mathrm{MAM}^{62}$ contemplan la necesidad de entrega de esta información. Cabe la duda si esta forma de asignación de defensores garantiza una defensa efectiva. ${ }^{63}$

Preguntado por el lazo de confianza necesaria entre el defensor y su cliente, un defensor penitenciario opina que "es bien perverso" pues "yo veo al interno como un sujeto de derecho, pero a la vez como un cliente" (DP 1). Describe un problema práctico que surge de ahí explicando que: "Creo que hoy en día cuando un interno, y creo está en todo su derecho, quiere un cambio de abogado, no le gusta, no se genera confianza, no hay feeling, cosas de trato, incluso pueden ser cosas de género, un montón de cosas; lo que se hace muchas veces es que ese cambio de abogado se ingresa como un reclamo en la Defensoría y eso significa un costo para el defensor. Entonces creo que es poco escuchado" (DP 1). Afirma que "el interno se ve mucho como un objeto de derechos (...) lo acompaño y lo llevó de la manito (...) es un sistema paternalista, hay poca autonomía, se ve poco la voluntariedad de él y él como un sujeto de derecho" (DP 1). ${ }^{64}$

Entendemos de estas intervenciones, que el derecho a la defensa no podría conformarse con la mera asignación de un abogado para que ejerza la representación, tal como está previsto en el MAM. Una defensa

${ }_{61}$ Así lo exige el artículo $\mathrm{N}^{\circ} 53$ de la Ley $\mathrm{N}^{\circ} 19.718$.

${ }^{62}$ Véase Capítulo I, numeral 2, letra c. del MAM.

${ }_{63}$ Sobre el marco legal del sistema de defensa licitada, véase: ARELLANO, Jaime (Dir.) Desafíos de la Reforma Procesal Penal en Chile: análisis retrospectivo a más de una década. Santiago de Chile: CEJA JSCA, 2015. pp. 100 y ss.

${ }_{64}$ En el mismo sentido, la defensora interamericana LÓPEZ PULEIO afirma que "el defensor no sustituye la voluntad de su representado, ni pasa a ocupar su lugar. Porque nadie podría arrogarse la facultad de ejercicio de un derecho que se estructura a partir de la idea de dignidad de la persona humana”. LÓPEZ PULEIO, M. Fernanda. El acceso a un defensor penal y sus ámbitos especialmente críticos. Revista Das Defensorías Públicas Do Mercosur, Brasilia, DF, $\mathrm{N}^{\circ} 3$, pp. 7-50, 2013. Punto 2.1. Disponible en: http:// www.pensamientopenal.com.ar/system/files/2015/04/doctrina40868. pdf Acceso en: 20 ago. 2019. 
efectiva requiere de una relación de confianza ${ }^{65}$ y confidencialidad entre el defendido y su representante. ${ }^{66}$

\subsubsection{CANTIDAD DE REQUERIMIENTOS}

Según los instructivos de la DPP, una solicitud de atención se convierte en requerimiento una vez que el equipo de la Defensoría ha realizado la primera entrevista al condenado. A cargo está el defensor asignado a la causa (aunque no necesariamente es el mismo que ha recibido la solicitud). Solo cuando la solicitud es presentada por el propio condenado y el defensor puede realizar la primera entrevista de forma inmediata (no está obligado), será el mismo defensor. Por regla general,

65 No obstante, vemos que ni siquiera el actual Código de Ética de la DPP contempla mayor referencia al tema de la confianza que debe existir entre defensor y defendido. DEFENSORÍA PENAL PÚBLICA. Código de Ética. 2016. Disponible en: http://www.dpp.cl/resources/descargas/codigo-etica-2016. pdf Acceso en: 15 mar. 2020. En cambio, el Código Deontológico para el Defensor(a) Penal Público(a) aprobado en 2010, todavía contemplaba en su primer Título como principio el de la confianza. El artículo $8^{\circ}$ establece que el defensor debía procurar "establecer una relación de confianza con su cliente, velando porque las decisiones que éste adopte en el proceso estén precedidas de la información necesaria”. RESOLUCIÓN EXENTA N²907, del 24 de septiembre de 2010. Aprueba Código Deontológico para del Defensor(a) Penal Público(a). Disponible en: http://www.dpp.cl/transparencia/files/ normativa/Rex.\%202907_2010.pdf Acceso en: 15 mar. 2020.

66 A nivel europeo, la Carta de Principios Esenciales de la Abogacía Europea y el Código Deontológico de la Abogacía Europea garantizan esta confidencialidad. Este último estipula "que las relaciones de confianza dependen directamente de la inexistencia de cualquier duda sobre la probidad, la honradez, la rectitud o la integridad del abogado. Para el abogado, estas virtudes tradicionales constituyen obligaciones profesionales" (Punto 2.2). En sus comentarios a la Carta de Principios, el Consejo de la Abogacía Europea resalta que "es esencial dentro de la función de abogado que sus clientes le refieran asuntos que nadie más conoce, informaciones personales muy íntimas (...) de acuerdo con la confianza que depositan en él. Sin la certeza de esta confidencialidad, no podría haber confianza”. CCBE. Carta de Principios Esenciales de la Abogacía Europea y el Código Deontológico de los Abogados Europeos. Comentario a la Carta de Principios Esenciales de la Abogacía Europea, Aprobado en la Sesión Plenaria del CCBE el 25.11.2006. p. 8. Disponible en: https://www.ccbe.eu/fileadmin/speciality_distribution/public/documents/ DEONTOLOGY/DEON_CoC/ES_DEON_CoC.pdf Acceso en: 16 ago. 2019. 
los defensores tienen un plazo de 20 días, desde el registro de la solicitud, para realizar la entrevista. ${ }^{67}$

Durante la entrevista, los defensores deben llenar una ficha con antecedentes personales (educación, trabajo y familia), de conducta y judiciales del solicitante. ${ }^{68}$ La ficha contempla un listado de materias que son atendidas por la DP. Se listan temas como salidas, traslados, atención de salud, entre otros. El tema de la violencia carcelaria, tratos crueles, inhumanos o degradantes, o las condiciones de reclusión, no encuentran mención específica. ${ }^{69}$ Durante la entrevista, el condenado puede hacer varios requerimientos que luego se tramitan a la vez. Todos ellos se registran en el SIGDP.

Si revisamos la cantidad de requerimientos que surgieron de las solicitudes de atención, constatamos que -en promedio- por cada solicitud de atención se ha presentado prácticamente un requerimiento. La siguiente tabla contempla este resultado mostrando la evolución de la cantidad de solicitudes de atención y de requerimientos desde el inicio del programa de DP. Podemos apreciar cómo en 7 años la cantidad de requerimientos a los que da lugar una solicitud de atención se ha mantenido casi estable. ${ }^{70}$

${ }^{67}$ Capítulo I, numeral 2 letras a. y b. del MAM.

${ }_{68}$ Capítulo I, numeral 2 letra d. del MAM.

69 Si nos detenemos en el MAM, encontramos que también cuenta con un listado de los requerimientos, pero tampoco se mencionan reclamos relacionados a las condiciones de reclusión y la violencia intracarcelaria. Es posible que algunos de estos puedan estar siendo registrados en otras categorías, como "otra vulneración de derechos".

70 En la Tabla $\mathrm{N}^{\circ} 1$, se mostró la cantidad de solicitues de atención por año. En un trabajo anterior hemos calculado este promedio en relación a un mayor número de requerimientos, ya que en la base de datos el mayor porcentaje de requerimientos corresponde a la categoría "requerimientos no formalizados" (23.917 en el 2018) y "requerimiento visita cárcel” (20.829 en el 2018) que representan el 33,6\% y 29,2\% del total anual, respectivamente. Sin embargo, estos no son en rigor "tipos" de requerimientos, más bien constituyen un error del sistema del registro. Por este motivo aquí no han sido considerados, lo que permite apreciar de manera más "limpia" la cantidad de requerimientos promedio que surgen a partir de cada solicitud de atención. La cantidad de "tipos" de requerimientos puede variar año a año, ya que se van agregando algunos, modificando o suprimiendo otros. En total (los 7 años) son 45, sin embargo, en el año 2018 -por ejemplo- solo son 37 categorías. 
TABLA $N^{\circ}$ 3. Evolución de la cantidad de requerimientos en relación a las solicitudes de atención

\begin{tabular}{|c|c|c|c|c|c|c|c|}
\hline $\mathrm{N}^{\circ} /$ Año & 2012 & 2013 & 2014 & 2015 & 2016 & 2017 & 2018 \\
\hline $\mathrm{N}^{\circ}$ de Requerimientos & 3782 & 8536 & 10720 & 12872 & 18134 & 20095 & 26467 \\
\hline $\begin{array}{c}\text { Promedio de } \\
\text { requerimientos por } \\
\text { solicitud de atención }\end{array}$ & 0,9 & 1,3 & 1,1 & 1,1 & 1,1 & 1,0 & 1,1 \\
\hline
\end{tabular}

Fuente: Elaboración propia en base a datos del SIGDP.

Podemos explicar estas cifras en relación a la proactividad de los defensores. Como señala un defensor "hay dos formas de hacer defensa penitenciaria” (DP 3). Explica que hay algunos defensores que tienen una actitud proactiva respecto a las necesidades del condenado y evalúan la situación de este más allá de la solicitud de atención coyuntural, para verificar si pueden hacer algo más. Lo ejemplifica afirmando que le llega un caso "por atención médica, lo veo por atención médica, lo cierro o le abro por atención médica, pero si tú estás viendo la entrevista (...) en el fondo está con conducta regular, postula a una escuela, ve reclamación de conducta..., entonces, en una solicitud ya tienes tres requerimientos" (DP 3). Otro defensor ratifica esto: "depende mucho del defensor y eso se refleja al final en la cifra" (DP 4). Otro agrega que "efectivamente, lo que se busca en la Defensoría creo yo, es explicarle al usuario qué es lo que podemos hacer, porque muchas veces no tienen conocimiento de lo que podemos hacer" (DP 2).

Sin embargo, hay otros defensores que se remiten estrictamente a la solicitud de atención recibida. Esto se explicaría porque "el sistema tampoco te incentiva a ser muy proactivo" (DP 2). Los defensores razonarían: "Me estoy sobrecargando yo de trabajo, voy a colapsar y no tengo ayuda" (DP 4) o bien, "en regiones dicen: van a pagar lo mismo, si yo tengo 20 o 60 causas y muchas veces dicen: si el interno [condenado] no lo pide ¿por qué lo vamos a hacer? Es porque el interno no sabe qué puede pedir (...) una vez entrevisté a cuatro jóvenes y había una quinta, le dije: ya, ¿qué quieres? y ella dijo: lo que sea, y yo: pero ¿cómo lo que sea? y me dijo: lo que sea, ayúdame en lo que sea. Al final terminamos rebajando una pena de 17 años a 11 años. La chica nunca me iba a decir que quería una modificación de pena, porque no sabía que eso se podía, pero si no haces eso, al final no se generan los requerimientos" (DP 4). 
Vemos que los defensores penitenciarios juegan un rol central a la hora de identificar los posibles requerimientos a la luz de las necesidades de las y los condenados, ayudándoles así en la activación de sus derechos.

Sin embargo, al parecer no existen incentivos institucionales para una actitud proactiva por parte de los defensores, por lo que el nivel que alcance dicha activación de derechos por parte de las personas privadas de libertad, dependerá fundamentalmente del compromiso y voluntad personal de cada defensor.

\subsubsection{MATERIA DE REQUERIMIENTOS}

Como se señaló, los instructivos de la DPP entregan directrices precisas para la atención en algunas materias (como libertad condicional y salud), no así en otras (como condiciones de reclusión, violencia carcelaria o malos tratos). Veremos que eso explica la ausencia de estas materias en los registros institucionales. Tan sólo en relación a celdas de castigo y/o aislamiento el defensor deber ejercer "todas las acciones necesarias para que las condiciones de la celda de aislamiento respeten la dignidad humana". ${ }^{71}$ También se contempla que cuando un defensor se entera de una agresión física a un condenado, debe constituirse "inmediatamente o a más tardar durante la mañana del día siguiente" en el respetivo establecimiento, para interceder por el(a) recluso(a). Al mismo tiempo debe informar de inmediato a la Defensoría Regional. La necesaria rapidez de informar a los niveles superiores de la DPP, se refleja en otra oración que concretiza el sentido de "inmediato" señalando que se debe usar "la vía más expedita". ${ }^{72}$ El instructivo no establece la necesidad de informar a la Fiscalía o policía de estos hechos, pese a que son posiblemente constitutivos de delito. Las estadísticas tampoco contemplan la necesidad de registrar la cantidad de denuncias presentadas en esa materia.

Consistente con esa orientación, el protocolo de difusión contempla directrices para difundir solo determinadas temáticas. El tema de maltratos o violencia no forma parte de ese catálogo. Hasta las bases de licitación, para ponderar la calificación de los profesionales que postulan a un contrato de licitación, estipulaban un catálogo exclusivo de temáticas de solicitudes

\footnotetext{
71 Capítulo III, numeral 3, c. del MAM.

72 Capítulo III., numeral 3, a. del MAM.
} 
valoradas como experiencia en asesoría jurídica a condenados. ${ }^{73} \mathrm{La}$ presentación de denuncias penales o disciplinarias por hechos de violencia sufridos por los condenados (por parte de funcionarios u otros internos) no está en el listado. Tampoco se encuentran solicitudes relacionadas a las condiciones de reclusión (acceso a baños, agua potable, alimentación, colchones, utensilios de limpieza e higiene, ingreso de paquetes, etc.).

En ese contexto, la información estadística muestra que, en los años 2016, 2017 y 2018, con la DP ya instalada en todo el país, la solicitud de libertad condicional fue el requerimiento más frecuente (representando el 13,1\% el 2016; el 18,3\% el 2017 y el 14,9\% el 2018), seguido por la solicitud de traslado de unidad penal (12,2\% el 2016; 12,7\% el 2017 y $13 \%$ el 2018), La tabla siguiente muestra los 15 requerimientos más frecuentes, los cuales en suma representan el 90\% de los requerimientos del periodo 2016-2018.

TABLA $N^{\circ}$ 4. Cantidad de requerimientos según materia. Años 2016-2018

\begin{tabular}{|l|c|c|c|c|c|c|}
\hline \multicolumn{1}{|c|}{ Materia Requerimiento/año } & $\mathbf{2 0 1 6}$ & $\mathbf{\%}$ & $\mathbf{2 0 1 7}$ & $\mathbf{\%}$ & $\mathbf{2 0 1 8}$ & $\mathbf{\%}$ \\
\hline Solicitud libertad condicional & 2380 & 13,1 & 3669 & 18,3 & 3932 & 14,9 \\
\hline Solicitud traslado unidad penal & 2213 & 12,2 & 2546 & 12,7 & 3453 & 13,0 \\
\hline Solicitud salida dominical & 1674 & 9,2 & 1791 & 8,9 & 2200 & 8,3 \\
\hline Solicitud abono de cautelares & 1398 & 7,7 & 1804 & 9,0 & 2145 & 8,1 \\
\hline Solicitud Pena Mixta (L.20.603) & 1588 & 8,8 & 1356 & 6,7 & 1656 & 6,3 \\
\hline Solicitud traslado módulo & 611 & 3,4 & 758 & 3,8 & 1199 & 4,5 \\
\hline Otra vulneración de derechos & 271 & 1,5 & 893 & 4,4 & 1375 & 5,2 \\
\hline Solicitud unificación de penas Art. 164 COT & 684 & 3,8 & 774 & 3,9 & 1065 & 4,0 \\
\hline Solicitud de Información Administrativa & 0 & 0,0 & 21 & 0,1 & 2146 & 8,1 \\
\hline Impugnación sanción disciplinaria & 460 & 2,5 & 446 & 2,2 & 881 & 3,3 \\
\hline Solicitud rebaja condena & 581 & 3,2 & 607 & 3,0 & 563 & 2,1 \\
\hline Solicitud participación acciones resocializador & 370 & 2,0 & 497 & 2,5 & 760 & 2,9 \\
\hline Solicitud sustitución multa Art. 49 CP & 499 & 2,8 & 493 & 2,5 & 644 & 2,4 \\
\hline Solicitud atención médica & 350 & 1,9 & 374 & 1,9 & 624 & 2,4 \\
\hline Solicitud abono de pena sustitutiva & 407 & 2,2 & 355 & 1,8 & 517 & 2,0 \\
\hline
\end{tabular}

Fuente: Elaboración propia en base a datos del SIGDP.

73 Resolución N 131, del 30 de septiembre de 2014. Formaliza acuerdo del Consejo de Licitaciones de defensa penal pública; Fija nuevo texto refundido de las bases administrativas y técnicas generales y anexos para la licitación pública del "Servicio de defensa penal de personas condenadas"; y establece lo que indica. Disponible en: http://www.dpp.cl/resources/upload/4827c3e5502e7f8081b0a3c42c03ce67.pdf Acceso en: 20 mar. 2020. Punto. 3.3. pp. 49-52. 
La categoría "otra vulneración de derechos" podría estar dando cuenta de una diversificación de la oferta de atención. Sin embargo, su porcentaje en el 2018 solo alcanza al 5,2\%. Los mismos defensores penitenciarios relatan que en un centro de reclusión (Santiago Sur) "los gendarmes frente a la oficina donde entrevistamos los abogados, también les pegan a los internos. Se escucha detrás de como una mampara, como un panel, y se escucha cómo les pegan" (DP 4). ${ }^{74}$ Sin embargo, manifiestan tener dificultades en responder a estos abusos pues "el problema es que después uno habla con el interno y el interno dice "no, es que yo contesté mal” (DP 3).

Desde esta perspectiva, podemos entender que el tipo de requerimientos responde principalmente a las definiciones de los instrumentos internos de la DPP. Materias normadas de forma específica encuentran su reflejo en las estadísticas, otras no. Los defensores casi no registran materias de atención no previstas expresamente en el MAM. Esto permite argumentar que las definiciones sobre la oferta de atención inciden en la configuración de la demanda.

74 Diversos informes del Instituto Nacional de Derechos Humanos (INDH) han constatado los graves problemas de hacinamiento, infraestructura, salubridad y violencia, entre otros, en las cárceles chilenas. Véase: INSTITUTO NACIONAL DE DERECHOS HUMANOS, INDH. Estudio de las condiciones carcelarias en Chile. Diagnóstico del cumplimiento de los estándares internacionales de derechos humanos sobre el derecho a la integridad personal 2016 - 2017. Santiago de Chile: Andros, 2018. Disponible en: https:// bibliotecadigital.indh.cl/bitstream/handle/123456789/1180/estudio-general-2016-2017.pdf?sequence $=3$ Acceso en: 16 ago. 2019. INSTITUTO NACIONAL DE DERECHOS HUMANOS, INDH. Estudio de las condiciones carcelarias en Chile 2014 - 2015. Seguimiento de recomendaciones y cumplimiento de estándares internacionales sobre el derecho a la integridad personal. Nuevamérica Impresores: Santiago de Chile, 2019. Disponible en: https://bibliotecadigital.indh.cl/bitstream/handle/123456789/1136/ estudio-general.pdf?sequence=1Acceso en: 16 ago. 2019. Por otra parte, el último informe de Naciones Unidas, Global study on homicide, da cuenta que Chile es el país con la mayor tasa de homicidios intracarcelarios a nivel latinoamericano. UNODC. Global study on homicide. 2019. Disponible en: https://www.unodc.org/unodc/en/data-and-analysis/global-study-on-homicide.html Acceso en: 19 nov. 2019. 


\subsubsection{CUMPlimiento de REQUisitos}

Los requerimientos deben cumplir una serie de requisitos para que puedan ser objeto de alguna tramitación (judicial o administrativa). Así, este hito implica en la práctica una suerte de "pre selección" por parte del defensor, entre requerimientos que este consideró que tenían sustento legal de aquellos que no. Este derecho le corresponde también al defensor en relación a recursos de amparo o protección deducidos por los propios condenados o sus familiares. El respectivo instructivo estipula que en estos casos el defensor penitenciario asume la representación "a menos que se trate de una acción o recurso improcedentes”. Sobre la improcedencia no puede decidir el defensor solo (tampoco el juez), sino lo debe hacer conjuntamente con la Defensoría Regional. ${ }^{75}$

Si examinamos la tabla $\mathrm{N}^{\circ} 5$, constatamos que, a partir del año 2013, prácticamente la mitad de los requerimientos cumplen los requisitos y la otra mitad o no los cumplen o no está determinado. ${ }^{76}$ Por otra parte, desde el año 2013, los requerimientos que cumplen los requisitos muestran una leve tendencia al alza, pasando de ser el 49,1\% a ser el 55,2\% en el 2018.

TABLA $N^{\circ} 5$. Evolución cumplimiento de requisitos de los requerimientos

\begin{tabular}{|c|c|c|c|c|c|c|c|c|c|c|c|c|c|c|}
\hline \multirow{2}{*}{ REQUERIMIENTOS } & \multicolumn{2}{|c|}{2012} & \multicolumn{2}{|c|}{2013} & \multicolumn{2}{|c|}{2014} & \multicolumn{2}{|c|}{2015} & \multicolumn{2}{|c|}{2016} & \multicolumn{2}{|c|}{2017} & \multicolumn{2}{|c|}{2018} \\
\hline & $\mathrm{N}^{\circ}$ & $\%$ & $\mathrm{~N}^{\circ}$ & $\%$ & $\mathrm{~N}^{\circ}$ & $\%$ & $\mathrm{~N}^{\circ}$ & $\%$ & $\mathrm{~N}^{\circ}$ & $\%$ & $\mathrm{~N}^{\circ}$ & $\%$ & $\mathrm{~N}^{\circ}$ & $\%$ \\
\hline Cumple requisitos & 744 & 19,7 & 4223 & 49,0 & 4853 & 45,3 & 6147 & 47,8 & 8864 & 48,9 & 10464 & 52,1 & 14613 & 55,2 \\
\hline No cumple requisitos & 749 & 19,8 & 3587 & 41,7 & 3881 & 36,2 & 4059 & 31,5 & 6087 & 33,6 & 6814 & 33,9 & 7351 & 27,8 \\
\hline No determinado & 2288 & 60,5 & 798 & 9,3 & 1986 & 18,5 & 2667 & 20,7 & 3183 & 17,6 & 2817 & 14,0 & 4503 & 17,0 \\
\hline Total & 3.781 & 100 & 8.610 & 100 & 10.720 & 100 & 12.873 & 100 & 18.134 & 100 & 20.095 & 100 & 26.467 & 100 \\
\hline
\end{tabular}

Fuente: Elaboración propia en base a datos del SIGDP.

Una explicación del aumento constante de los requerimientos que cumplen con los requisitos, podrían ser los indicadores que emplea la DPP para el control de las actividades del contrato suscrito con el respectivo prestador. Uno de los indicadores mide "Requerimiento presentado a tramitación dentro

75 Capítulo III., numeral 3.b. del MAM.

76 Los requerimientos no determinados son aquellos casos en que se ha producido el cumplimiento de la condena, el traslado de región o recinto penitenciario, el desistimiento por parte del condenado, una fuga o el deceso del condenado. 
del plazo". Si el nivel es menor a $60 \%$ no se cumple el indicador. ${ }^{77}$ Pese a que esta tendencia de aumento de requerimientos aceptados es positiva, se constata que en general la mitad de los requerimientos no se transforman en una gestión propiamente tal. En estas demandas los condenados no logran movilizar sus derechos. Si bien nada garantiza que las peticiones que hagan los reclusos tengan un respaldo legal, resulta difícil explicar el alto porcentaje de requerimientos que no corresponderían a una petición viable jurídicamente. Si consideramos además que esta decisión queda al análisis exclusivo del defensor, vemos como la práctica refleja lo señalado por Blankenburg y Bruinsma, que entre la legislación y su aplicación se encuentra la práctica jurídica que ejerce su propio poder de definir lo que debe ser válido en la ley. ${ }^{78}$

En la tabla siguiente, podemos observar el cumplimiento de requisitos según materia del requerimiento. Para ello observamos los 15 tipos de requerimientos más frecuentes (según vimos anteriormente en la tabla $\mathrm{N}^{\circ} 4$ ).

TABLA $N^{\circ}$ 6. Cumplimiento de requisitos de los requerimientos. Año 2018

\begin{tabular}{|l|c|c|c|c|c|c|}
\hline \multirow{2}{*}{ REQUERIMIINTOS } & \multicolumn{2}{|c|}{ Cumple requisitos } & \multicolumn{2}{c|}{ No cumple requisitos } & \multicolumn{2}{c|}{ No determinado } \\
\cline { 2 - 7 } & $\mathbf{N}^{\circ}$ & $\mathbf{9}$ & $\mathbf{N}^{\circ}$ & $\mathbf{9}$ & $\mathbf{N}^{\circ}$ & $\mathbf{\%}$ \\
\hline Solicitud libertad condicional & 2350 & $\mathbf{5 9 , 8}$ & 1187 & $\mathbf{3 0 , 2}$ & 395 & $\mathbf{1 0 , 0}$ \\
\hline Solicitud traslado unidad penal & 2392 & $\mathbf{6 9 , 3}$ & 390 & $\mathbf{1 1 , 3}$ & 671 & $\mathbf{1 9 , 4}$ \\
\hline Solicitud salida dominical & 761 & $\mathbf{3 4 , 6}$ & 1191 & $\mathbf{5 4 , 1}$ & 248 & 11,3 \\
\hline Solicitud abono de cautelares & 1016 & $\mathbf{4 7 , 4}$ & 615 & $\mathbf{2 8 , 7}$ & 514 & $\mathbf{2 4 , 0}$ \\
\hline Solicitud Pena Mixta (L.20.603) & 491 & $\mathbf{2 9 , 6}$ & 893 & $\mathbf{5 3 , 9}$ & 272 & $\mathbf{1 6 , 4}$ \\
\hline Solicitud traslado módulo & 728 & $\mathbf{6 0 , 7}$ & 267 & $\mathbf{2 2 , 3}$ & 204 & $\mathbf{1 7 , 0}$ \\
\hline Otra vulneración de derechos & 733 & $\mathbf{5 3 , 3}$ & 313 & $\mathbf{2 2 , 8}$ & 329 & $\mathbf{2 3 , 9}$ \\
\hline Solicitud unificación de penas Art. 164 COT & 205 & $\mathbf{1 9 , 2}$ & 617 & $\mathbf{5 7 , 9}$ & 243 & $\mathbf{2 2 , 8}$ \\
\hline Solicitud de Información Administrativa & 2034 & $\mathbf{9 4 , 8}$ & 29 & $\mathbf{1 , 4}$ & 83 & $\mathbf{3 , 9}$ \\
\hline Impugnación sanción disciplinaria & 357 & $\mathbf{4 0 , 5}$ & 237 & $\mathbf{2 6 , 9}$ & 287 & $\mathbf{3 2 , 6}$ \\
\hline Solicitud rebaja condena & 160 & $\mathbf{2 8 , 4}$ & 254 & $\mathbf{4 5 , 1}$ & 149 & $\mathbf{2 6 , 5}$ \\
\hline Solicitud participación acciones resocializadoras & 488 & $\mathbf{6 4 , 2}$ & 138 & $\mathbf{1 8 , 2}$ & 134 & $\mathbf{1 7 , 6}$ \\
\hline Solicitud sustitución multa Art. 49 CP & 382 & $\mathbf{5 9 , 3}$ & 114 & $\mathbf{1 7 , 7}$ & 148 & $\mathbf{2 3 , 0}$ \\
\hline Solicitud atención médica & 465 & $\mathbf{7 4 , 5}$ & 32 & $\mathbf{5 , 1}$ & 127 & $\mathbf{2 0 , 4}$ \\
\hline Solicitud abono de pena sustitutiva & 245 & $\mathbf{4 7 , 4}$ & 146 & $\mathbf{2 8 , 2}$ & 126 & $\mathbf{2 4 , 4}$ \\
\hline
\end{tabular}

Fuente: Elaboración propia en base a datos del SIGDP.

77 RESOLUCIÓN EXENTA No 355 del 26 de septiembre de 2016. Aprueba contrato para prestación del servicio de defensa penal pública con Asesorías Jurídicas Integrales SpA, en la zona Z1P (Santiago) de la Región Metropolitana Norte. Punto Décimo Sexto. Disponible en: https://ciperchile.cl/wp-content/uploads/contrato -asesor\%C3\%ADas-jur\%C3\%ADdicas-integrales_2.pdf Acceso en: 15 mar. 2020.

78 BLANKENBURG, Erhard y BRUINSMA, Freek. Op. cit. p. 345. 
El porcentaje más alto de cumplimiento de requisitos en el año 2018 es en la solicitud de información administrativa (94,8\%); solicitud de atención médica (74,5\%); solicitud de traslado de unidad penal (69,3\%); y solicitud de participación de acciones resocializadoras (64,2\%). Por el contrario, los menores porcentajes de cumplimiento de requisitos se observan en la solicitud de unificación de penas (Art. 164 COT) con un $19,2 \%$; solicitud de rebaja de condena $(28,4 \%)$; solicitud de pena mixta (29,6\%); y solicitud de salida dominical (34,6\%).

Podemos interpretar estos resultados señalando que, en primer lugar, no se observa una relación directa entre la frecuencia de un requerimiento y su porcentaje de cumplimiento de requisitos. Es decir, los requerimientos más frecuentes no son necesariamente aquellos que cumplen más los requisitos, ni los menos frecuentes son los que tienen menores porcentajes de cumplimiento de requisitos. Por otra parte, lo que sí podrían estar revelando estos resultados, es que aquellos requerimientos que dependen fundamentalmente de gestiones ante la autoridad administrativa, -y en principio representan una menor complejidad- tienden a cumplir en un mayor porcentaje los requisitos, a diferencia de aquellos que implican gestiones de tipo judicial y que muestran porcentajes de cumplimiento de requisitos más bajos.

\section{CONCLUSIONES}

\subsection{La Defensa Penitenciaria perfila su propia demanda de atención}

Vimos que la atención que brinda la Defensa Penitenciaria no refleja únicamente la demanda de atención expresada por las personas condenadas. La activación de derechos por parte de personas privadas de libertad se relaciona más bien con la forma en cómo se organiza y funciona la oferta de atención de la Defensa Penitenciaria. ${ }^{79}$ No es la demanda que perfila la oferta, sino es la oferta la que determina la demanda.

79 Ese hallazgo encuentra su eco también en la opinión de Alberto Bovino cuando afirma que, "la legalidad no ha penetrado a la cárcel, principalmente, por las prácticas de los operadores de la justicia penal”. BOVINO, Alberto. 
Hemos identificado una serie de factores institucionales (oferta) que inciden en la magnitud y tipo de la demanda: la insuficiente cantidad de defensores asignados a determinados centros de reclusión; las dificultades de accesibilidad a los defensores; la poca relevancia otorgada a la relación de confianza entre el defendido y su representante; la falta de incentivos institucionales para una actitud proactiva de los defensores destinada a identificar derechos vulnerados de los condenados; y la ausencia de control de los filtros que hace el defensor respecto al cumplimiento de requisitos.

Se suma a lo anterior, que las directrices contenidas en la normativa interna y en las bases de licitación, definen las materias que deben ser objeto de atención. Desde una perspectiva crítica, consideramos que la DPP no es una ONG. No puede escoger las materias que atiende, tal como lo hacen las instituciones mencionadas por Blankenburg (véase arriba). Por el contrario, debería guiarse por las necesidades de defensa no satisfechas ${ }^{80}$, en vez de establecer sus propios criterios para lo que consideran necesidades importantes. Su rol es garantizar el derecho a la defensa jurídica. ${ }^{81}$ En ese marco, se debe garantizar la igual protección en el ejercicio de los derechos en general con una defensa que cuente con autonomía funcional y no con un catálogo de materias seleccionadas de atención. ${ }^{82}$ La institución debe propender al cumplimiento de los

Control judicial de la privación de libertad y derechos humanos. Revista Jurídica, $\mathrm{N}^{\circ}$ 17, pp. 1-23, 2004. p. 1.

80 Los Principios Básicos sobre la Función de los Abogados respaldan nuestra conclusión. Estipulan que "los abogados, al proteger los derechos de sus clientes y defender la causa de la justicia, procurarán apoyar los derechos humanos y las libertades fundamentales reconocidos por el derecho nacional e internacional”. Principio 14. ONU. Principios Básicos sobre la Función de los Abogados. Aprobados por el Octavo Congreso de las Naciones Unidas sobre Prevención del Delito y Tratamiento del Delincuente, celebrado en La Habana (Cuba) del 27 de agosto al 7 de septiembre de 1990. Disponible en: https://www.oacnudh.org.gt/estandares/docs/Instrumentos/Justicia/Principios4.pdf Acceso en: 16 ene. 2020.

81 Artículo $\mathrm{N}^{\circ}$ 19.3, inc. 2 de la Constitución Política de la República de Chile.

82 GARCÍA, CONTRERAS y MARTÍNEZ explican que "la dimensión de defensa se vincula materialmente con la igual protección que da el legislador en el ejercicio de los derechos". Pues "el propio mundo jurídico es constitutivo de un lenguaje nuevo, técnico, sistemático e impenetrable". Eso es "particularmente sensible en amplios sectores de la ciudadanía, en ámbitos socioeconómicamente postergados y en minorías especiales". Afirman que "por lo 
objetivos y las demandas de derechos que se encuentran previstos en su estatuto propio (Tratados Internacionales de DDHH, Constitución, Leyes y Reglamentos e instrucciones), lo que en el caso de la Defensa Pública de Chile sólo parece reflejarse en el discurso formal.

Direccionar de la manera descrita la demanda, contraviene la autonomía funcional de los defensores y así el derecho a la defensa. La Corte Interamericana de Derechos Humanos ha reiterado en el caso Ruano Torres y otros vs. El Salvador que la institución de la defensa pública, como medio a través del cual el Estado garantiza el derecho a la defensa, debe "contar con defensores idóneos y capacitados que puedan actuar con autonomía funcional". ${ }^{33}$ En el mismo sentido encontramos que la Asamblea General de la OEA, en dos resoluciones que abarcan la autonomía de la defensa pública oficial como garantía de acceso a la justicia, resolvió “destacar la importancia de la independencia, autonomía funcional, financiera y/o presupuestaria, de la defensa pública oficial, como parte de los esfuerzos de los Estados Miembros para garantizar un servicio público eficiente, libre de injerencias y controles indebidos por parte de otros poderes del Estado que afecten su autonomía funcional y cuyo mandato sea el interés de su defendido o defendida". ${ }^{84}$

Por otra parte, la defensa penitenciara no es una oferta eficiente, desde que existe una baja población que tiene acceso a este servicio, acceso

tanto, en el corazón de las respuestas del sistema judicial está la perspectiva de proscribir la indefensión”. GARCÍA, Gonzalo; CONTRERAS, Pablo y MARTÍNEZ, Victoria. Diccionario Constitucional Chileno. Santiago de Chile: Editorial Hueders, 2016. pp. 277 y ss.

83 Corte IDH, Caso Ruano Torres y Otros vs. El Salvador, Sentencia del 05 de octubre de 2015, Serie C No. 303, párr. 157.

84 Asamblea General de la OEA, Resolución AG/RES. 2801 (XLIII-O/13), Hacia la autonomía de la defensa pública oficial como garantía de acceso a la justicia, 5 de junio de 2013, párr. 5;

Disponible en: http://www.oas.org/es/sla/ddi/docs/AG-RES_2801_XLIII -O-13.pdf Acceso en: 30 jun. 2020.

Resolución AG/RES. 2821 (XLIV-O/14), Hacia la autonomía y fortalecimiento de la Defensa Pública Oficial como garantía de acceso a la justicia, 10 de junio de 2014, párr. 6

Disponible en: http://www.oas.org/es/sla/ddi/docs/AG-RES_2821_XLIV -O-14.pdf Acceso en: 30 jun. 2020. 
que se ve reducido no por cuestiones objetivas, ya que este queda sujeto a la discrecionalidad de los diversos agentes (administración penitenciaria, defensores y otras personas privadas de libertad).

La visión institucional contemplada en los distintos instrumentos de gestión (como las bases de licitación y el MAM), refleja una concepción donde se despersonaliza la defensa y se la entiende como la prestación de cualquier otro servicio, sea de transporte público o de agua potable, que además se puede tercerizar. ${ }^{85}$ Es por eso que el tema de la necesaria confianza entre el defensor y representado no encuentra mayor reflejo en la normativa interna. En ese contexto, se hace entendible la afirmación de un defensor que sentía que se trataba a los condenados como "objetos" más que como sujetos de derecho, despersonalizando así la defensa de las y los condenados.

\subsection{La selectividad atenta contra el objetivo de la Defensa Penitenciaria.}

El estudio comprobó, que la DP no atiende de manera prioritaria violaciones a los derechos constitucionales y humanos causados por las condiciones de reclusión y la violencia intracarcelaria (véase tabla 4 y 6). Actualmente, ni siquiera se cuenta con datos exactos para saber si los defensores reciben denuncias de este tipo. Es elocuente que en los instructivos internos no aparezcan reglas específicas de actuación cuando los defensores constatan tratos inhumanos, crueles y degradantes. En la misma línea, de un aparente desinterés institucional, podemos entender la ausencia de mención del deber de denunciar ante la Fiscalía o policía agresiones físicas sufridas por sentenciados. ${ }^{86}$ Parece ser, que en las

85 En ese contexto parece acertado lo afirmado por BINDER, que "en aquellos países donde se han desarrollado mecanismos de asistencia jurídica, las preocupaciones de las instituciones y del personal que presta la asistencia jurídica predominan con frecuencia sobre las de los "consumidores" de los servicios jurídicos”. BINDER, Alberto; CAPE, Ed y NAMORADZE, Zaza. Defensa penal efectiva en América Latina. Bogotá: Ediciones Antropos Ltda. 2015. p. 7.

86 Incluso los Principios y Directrices de las Naciones Unidas sobre el acceso a la asistencia jurídica en los sistemas de justicia penal (2012), enfatizan que la asistencia debe servir para que los reclusos puedan "interponer apelaciones y presentar solicitudes relacionadas con el trato que reciben y las condiciones de su reclusión”. Principio 47.c). UNODC. Principios y directrices de las 
directrices internas lo importante es el informar a las instancias superiores de la DPP. Esto sirve para poder controlar, entre otros, cualquier posible conflicto con el operador penitenciario o el Ministerio de Justicia y Derechos Humanos.

Esta falta de atención profundiza la desesperanza aprendida o resignación de los reclusos y fomenta así su proceso de prisionización. ${ }^{87}$ Desde su punto de vista, las malas condiciones de vida, incluso la violencia, forman parte del castigo.$^{88}$ La realidad nacional muestra también que estas situaciones son parte de la vida cotidiana de la población penal. Es justo este hecho el que debería encontrar su contraste en una defensa mucho más proactiva en atender a las condiciones de vida y la violencia hacia y entre las personas recluidas.

\subsection{RECOMENDACIONES}

A una década del inicio de la DP, la meta de gestión no debería ser la de entregar más de lo mismo, sino de reenfocar la oferta. A su vez, se debería fortalecer la autonomía funcional del servicio de defensa penitenciaria a fin de garantizar efectivamente tal derecho. Es necesario modificar el catálogo de atención incluyendo directrices expresas para la defensa contra condiciones inhumanas de reclusión y violencia carcelaria. Los distintos instrumentos de gestión, específicamente el MAM y la ficha de registro de la primera entrevista, deberían entregar las orientaciones

Naciones Unidas sobre el acceso a la asistencia jurídica en los sistemas de justicia penal. Disponible en: https://www.unodc.org/documents/justice -and-prison-reform/13-86673_ebook-Spanish.pdf Acceso en: 24 ago. 2019.

La prisionización se define como "la asimilación e internalización de la subcultura carcelaria por parte del sujeto, que no solo supone la aceptación de normas y códigos institucionales (de la cárcel como institución), sino, sobre todo, de las propias reglas y jerarquías entre los internos". CLEMMER, Donald. The prison community. Nueva York: Rinehart \& Winston, 1958, p. 96.

HORVITZ explica que la cárcel naturaliza otras violaciones a derechos constitucionales, haciendo aparecer estos excesos "como 'inherentes' al castigo, a pesar de que constituyen una agravación injustificada de la pena”. HORVITZ, M. Inés. La insostenible situación de la ejecución de las penas privativas de libertad: ¿vigencia del Estado de derecho o estado de naturaleza? Revista Política Criminal, Santiago de Chile, v. 13, n 26, pp. 904-951, p. 928. 2018. 
respectivas y debiesen ser mejorados. También esto debiera ser parte de las directrices de los coordinadores regionales. A su vez es necesario repensar el modelo de atención, en particular, aumentar la dotación de defensores, establecer incentivos adecuados y mejorar las condiciones de accesibilidad a estos por parte de las y los condenados. Se debe evitar que la atención a un condenado dependa de otra persona privada de libertad o del personal penitenciario, la DPP debería volver a difundir su oferta en los distintos módulos, calles y pabellones de las cárceles, acercando su oferta a los usuarios. A nivel latinoamericano, otras Defensorías Públicas, como la ecuatoriana, han mejorado su atención abriendo oficinas en las cárceles. De esta manera el defensor no llega "de visita".

Para movilizar los derechos, en cantidad y calidad adecuadas, y cumplir con el objetivo institucional de mejorar la aplicación de las garantías constitucionales y el acceso a la justicia de los condenados privados de libertad, la oferta de atención institucional de la DP debe adecuarse a todas las necesidades de defensa de la población penal, y no al revés. Pues "sin defensa no hay justicia" ${ }^{89}$, menos aún en la cárcel.

\section{REFERENCIAS}

ARELLANO, Jaime (Dir.) Desafíos de la Reforma Procesal Penal en Chile: análisis retrospectivo a más de una década. Santiago de Chile: CEJA JSCA, 2015.

BINDER, Alberto; CAPE, Ed y NAMORADZE, Zaza. Defensa penal efectiva en América Latina. Bogotá: Ediciones Antropos Ltda. 2015.

BLANKENBURG, Erhard. Mobilisierung des Rechts. Eine Einführung in die Rechtssoziologie. Heidelberg: Springer Verlag. 1995.

BLANKENBURG, Erhard y BRUINSMA, Freek. The role of courts in the Netherlands and Germany- Dutch Legal Culture Compared. En: GESSNER Volkmar; HOELAND Armin y VARGA Csaba (Eds.). European Legal Cultures. Aldershot: Dartmouth, 1996, pp. 344 a 352.

BOVINO, Alberto. Control judicial de la privación de libertad y derechos humanos. Revista Jurídica, $\mathrm{N}^{\circ} 17$, pp. 1-23, 2004. Disponible en: https://www.

89 "Sin defensa no hay justicia" es el lema institucional de la Defensa Penal Pública chilena. 
revistajuridicaonline.com/2004/01/el-control-judicial-de-la-privacion-de-libertady-derechos-humanos/ Acceso en: 27 ene. 2019.

CALDERÓN, Rodrigo. Delincuencia, Políticas de estado y derechos humanos-a propósito de la cuestión penitenciaria en Chile. Santiago de Chile; RIL Editores, 2015.

CARNEVALI, Raúl y MALDONADO, Francisco. El tratamiento penitenciario en Chile. Especial atención a problemas de constitucionalidad. Revista Ius et Praxis, año 19, n. 2, pp. 385 - 418, 2013. Disponible en: https://scielo.conicyt.cl/pdf/ iusetp/v19n2/art12.pdf Acceso en: 16 jun. 2020.

CASTRO, Álvaro. Estándares de la Corte Interamericana de Derechos Humanos en materia de imputados y condenados privados de libertad. Anuario de Derechos Humanos, n. 14, pp. 35-54, 2018. Disponible en: https://revistas.uchile.cl/index. php/ADH/article/download/49161/54183/ Acceso en: 16 jun. 2020.

CCBE. Carta de Principios Esenciales de la Abogacía Europea y el Código Deontológico de los Abogados Europeos. Comentario a la Carta de Principios Esenciales de la Abogacía Europea, Aprobado en la Sesión Plenaria del CCBE el 25.11.2006. p. 8. Disponible en: https://www.ccbe.eu/fileadmin/speciality_ distribution/public/documents/DEONTOLOGY/DEON_CoC/ES_DEON_CoC. pdf Acceso en: 16 ago. 2019.

CENTRO DE SISTEMAS PÚBLICOS. Departamento de Ingeniería Industrial, Facultad de Ciencias Físicas y Matemáticas, Universidad de Chile. Evaluación del Programa de Licitaciones de Defensa Penal Pública de la Defensoría Penal Pública. Informe Final. 2017. Disponible en: http://www.sistemaspublicos.cl/wp-content/ uploads/2018/07/DIPRES-DPP-Informe-Final.pdf Acceso en: 20 ago. 2019.

CENTRO DE ESTUDIOS JUSTICIA Y SOCIEDAD. Instituto de Sociología de la P. Universidad Católica de Chile (2019). Auditoría Externa de Actuaciones Mínimas para la Defensa Penitenciaria 2018-2019. Disponible en: http://www. dpp.cl/resources/upload/efb3ac4f6a04a85caa2d0e898bf28f05.pdf Acceso en: 16 ago. 2019.

CESANO, José. Derecho Penitenciario: Aproximación a sus Fundamentos. Córdova: Alveroni Ediciones, 2009.

CLEMMER, Donald. The prison community. Nueva York: Rinehart \& Winston, 1958.

CONTESSE, Javier y CONTRERAS, Lautaro (eds.). La insostenible situación de las cárceles en Chile: debate sobre la prisión y los derechos humanos. Santiago: Editorial Jurídica de Chile, 2019. 
DEFENSORÍA PENAL PÚBLICA. Código de Ética. 2016. Disponible en: http:// www.dpp.cl/resources/descargas/codigo-etica-2016.pdf Acceso en: 15 mar. 2020.

FEEST, Johannes. Elaboración y contenido de la ley penitenciaria y su impacto en el sistema penitenciario alemán. Revista de Estudios Criminológicos y Penitenciarios, Santiago de Chile, $\mathrm{N}^{\circ}$ 7. Gendarmería de Chile/UNICRIM, pp. 17 - 28, 2005.

FERNÁNDEZ, Marco Antonio. Derecho penitenciario chileno. Problemas en torno a su naturaleza jurídica. Santiago de Chile: Hammurabi, 2019.

FUCITO, Felipe. Sociología del Derecho. El orden jurídico y sus condicionantes sociales. Buenos Aires: Editorial Universidad, 1999.

GARCÍA, Gonzalo; CONTRERAS, Pablo y MARTÍNEZ, Victoria. Diccionario Constitucional Chileno. Santiago de Chile: Editorial Hueders, 2016.

GENDARMERÍA DE CHILE. Compendios Estadísticos. Disponibles en: https:// www.gendarmeria.gob.cl/estadisticas_compendios.html Acceso en: 10 nov. 2019.

GÓMEZ, Gastón. Derechos Fundamentales y Recurso de Protección. Santiago de Chile: Universidad Diego Portales, 2005.

HORVITZ, M. Inés. La insostenible situación de la ejecución de las penas privativas de libertad: ¿vigencia del Estado de derecho o estado de naturaleza? Revista Política Criminal, Santiago de Chile, v. 13, n 26, pp. 904-951, 2018 http://dx.doi. org/10.4067/S0718-33992018000200904

INSTITUTO NACIONAL DE DERECHOS HUMANOS, INDH. Estudio de las condiciones carcelarias en Chile. Diagnóstico del cumplimiento de los estándares internacionales de derechos humanos sobre el derecho a la integridad personal 2016 2017. Santiago de Chile: Andros, 2018. Disponible en: https://bibliotecadigital. indh.cl/bitstream/handle/123456789/1180/estudio-general-2016-2017. pdf?sequence=3 Acceso en: 16 ago. 2019.

INSTITUTO NACIONAL DE DERECHOS HUMANOS, INDH. Estudio de las condiciones carcelarias en Chile 2014 - 2015. Seguimiento de recomendaciones y cumplimiento de estándares internacionales sobre el derecho a la integridad personal. Nuevamérica Impresores: Santiago de Chile, 2019. Disponible en: https:// bibliotecadigital.indh.cl/bitstream/handle/123456789/1136/estudio-general. pdf?sequence=1Acceso en: 16 ago. 2019.

INSTITUTO NACIONAL DE DERECHOS HUMANOS. Informe anual 2012. Disponible en: http://www.indh.cl/wp-content/uploads/2012/12/Inf-AnualINDH12-WEB.pdf Acceso en: 28 de junio de 2020 
KENDALL, Stephan. Tutela judicial efectiva en la relación jurídica penitenciaria. Santiago de Chile: Librotecnia, 2010.

LEÓN, Marco Antonio. Encierro y Corrección. La Configuración de un Sistema de Prisiones en Chile (1800 - 1911) Tomo II. y III. Santiago de Chile: Universidad Central de Chile, 2003.

LIBEDINSKY, Sofía. Rediseño del Modelo de Defensa Penitenciaria para Adultos Privados de Libertad en el nuevo Sistema Procesal Penal. Revista Estudios de Políticas Públicas, Santiago de Chile, vol. 1, pp. 226-245, 2016. Disponible en: https://www.researchgate.net/publication/292347188_Rediseno_del_modelo_ de_defensa_penitenciaria_para_adultos_privados_de_libertad_en_el_nuevo_ sistema_procesal_penal Acceso en: 15 agosto, 2019.

LÓPEZ PULEIO, M. Fernanda. El acceso a un defensor penal y sus ámbitos especialmente críticos. Revista Das Defensorías Públicas Do Mercosur, Brasilia, DF, $N^{\circ} 3$, pp. 7-50, 2013. Disponible en: http://www.pensamientopenal.com.ar/ system/files/2015/04/doctrina40868.pdf Acceso en: 20 ago. 2019.

MAÑALICH, Juan Pablo. El derecho penitenciario entre la ciudadanía y los derechos humanos. Revista Derecho y Humanidades, n. 18, pp. 163-178, 2011.

OEA. Asamblea General: Resolución AG/RES. 2801 (XLIII-O/13), Hacia la autonomía de la defensa pública oficial como garantía de acceso a la justicia, 5 de junio de 2013. Disponible en: http://www.oas.org/es/sla/ddi/docs/AGRES_2801_XLIII-O-13.pdf Acceso en: 30 jun. 2020.

OEA. Asamblea General: Resolución AG/RES. 2821 (XLIV-O/14), Hacia la autonomía y fortalecimiento de la Defensa Pública Oficial como garantía de acceso a la justicia, 10 de junio de 2014. Disponible en: http://www.oas.org/es/sla/ddi/ docs/AG-RES_2821_XLIV-O-14.pdf Acceso en: 30 jun. 2020.

ONU. Principios Básicos sobre la Función de los Abogados. Aprobados por el Octavo Congreso de las Naciones Unidas sobre Prevención del Delito y Tratamiento del Delincuente, celebrado en La Habana (Cuba) del 27 de agosto al 7 de septiembre de 1990. Disponible en: https://www.oacnudh.org.gt/estandares/docs/Instrumentos/ Justicia/Principios4.pdf Acceso en: 16 ene. 2020.

PÉREZ-PERDOMO, Rogelio. Versión escrita de la conferencia pronunciada por el galardonado al recibir el Premio Internacional de Investigación en Derecho "Héctor Fix-Zamudio" 2014. "El derecho comparado y la comparación de culturas jurídicas. Una perspectiva latinoamericana”. Boletín Mexicano de Derecho Comparado, año XLIX, N 146, pp. 477-504, 2016, Disponible en: https://revistas.juridicas.unam. $\mathrm{mx} /$ index.php/derecho-comparado/issue/view/537 Acceso en: 27 en. 2019 
SALINERO, M. Alicia. Programa de Defensa Penitenciaria: Una contribución al acceso a la justicia, Revista Debates Penitenciarios, CESC, Santiago, $N^{\circ} 19$, pp. 3-22, 2014. https://www.cesc.uchile.cl/debates_penitenciarios_19.pdf Acceso en: 27 en. 2019.

STIPPEL, Jörg. Cárcel, derecho y política. Santiago: LOM Ediciones, 2013.

STIPPEL, Jörg. Las cárceles y la búsqueda de una política criminal para Chile. Santiago: LOM Ediciones, 2006.

UNODC. Global study on homicide. 2019. Disponible en: https://www.unodc. org/unodc/en/data-and-analysis/global-study-on-homicide.html Acceso en: 19 nov. 2019.

UNODC. Principios y directrices de las Naciones Unidas sobre el acceso a la asistencia jurídica en los sistemas de justicia penal. Disponible en: https://www. unodc.org/documents/justice-and-prison-reform/13-86673_ebook-Spanish.pdf Acceso en: 24 ago. 2019.

\section{Informações adicionais e declarações dos autores (integridade científica)}

Agradecimentos (acknowledgement): El desarrollo de la parte empírica de este trabajo fue financiado por el Fondo Interno de Investigación I+D 2016, Código CIP16018. Universidad Central de Chile.

Declaração de conflito de interesses (conflict of interest declaration): os autores confirmam que não há conflitos de interesse na realização das pesquisas expostas e na redação deste artigo.

Declaração de autoria e especificação das contribuições (declaration of authorship): todas e somente as pessoas que atendem os requisitos de autoria deste artigo estão listadas como autores; todos os coautores se responsabilizam integralmente por este trabalho em sua totalidade. 
- Jörg Alfred Stippel: projeto e esboço inicial (conceptualization), desenvolvimento da metodologia (methodology), coleta e análise de dados (data curation), levantamento bibliográfico (investigation), revisão bibliográfica (investigation), redação (writing - original draft), participação ativa nas discussões dos resultados (validation), revisão crítica com contribuições substanciais (writing - review and editing), aprovação da versão final.

- Paula Carolina Medina: desenvolvimento da metodologia (methodology), coleta e análise de dados (data curation), levantamento bibliográfico (investigation), revisão bibliográfica (investigation), redação (writing - original draft), participação ativa nas discussões dos resultados (validation), revisão crítica com contribuições substanciais (writing - review and editing), aprovação da versão final.

- Rodrigo Lillo: coleta e análise de dados (data curation), levantamento bibliográfico (investigation), revisão bibliográfica (investigation), redação (writing - original draft), participação ativa nas discussões dos resultados (validation), revisão crítica com contribuições substanciais (writing - review and editing), aprovação da versão final.

Declaração de originalidade (declaration of originality): os autores apontam que o texto aqui publicado foi depositado como postprint em 3.8.2020 (https://doi.org/10.1590/SciELOPreprints.1043). Futura republicação somente se realizará com a indicação expressa da referência desta publicação original; também atestam que não há plágio de terceiros ou autoplágio. 
Dados do processo editorial

(http://www.ibraspp.com.br/revista/index.php/RBDPP/about/editorialPolicies)

- Recebido em: 31/03/2020

- Controle preliminar e verificação de plágio: 28/04/2020

- Avaliação 1: 04/05/2020

- Avaliação 2: 05/05/2020

- Avaliação 3: 13/05/2020

- Avaliação 4: 14/05/2020

- Decisão editorial preliminar: 01/06/2020

- Retorno rodada de correções: 02/07/2020

- Decisão editorial final: 02/07/2020

- Depósito postprint: 03/08/2020 (https://doi. org/10.1590/SciELOPreprints.1043)

\section{Equipe editorial envolvida}

- Editor-chefe: 1 (VGV)

- Editor-assistente: 1 (PMM)

- Revisores: 4

\section{COMO CITAR ESTE ARTIGO:}

STIPPEL, Jörg Alfred; MEDINA, Paula Carolina; LILLO, Rodrigo. Obstáculos en la activación de derechos en el marco de la defensa penitenciaria chilena. Revista Brasileira de Direito Processual Penal, Porto Alegre, vol. 6, n. 3, p. 1735-1775, set./dez. 2020. https://doi.org/10.22197/rbdpp.v6i3.356

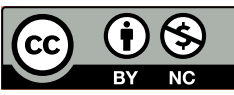

Esta obra está licenciada com uma Licença Creative Commons Atribuição-NãoComercial 4.0 Internacional. 